Purdue University

Purdue e-Pubs

Purdue CIBER Working Papers

Krannert Graduate School of Management

$1-1-1994$

\title{
Patent Races, Product Standards, and International Competition
}

Richard Jensen

University of Kentucky

Marie Thursby

Purdue University

Follow this and additional works at: http:// docs.lib.purdue.edu/ciberwp

Jensen, Richard and Thursby, Marie, "Patent Races, Product Standards, and International Competition" (1994). Purdue CIBER

Working Papers. Paper 92.

http://docs.lib.purdue.edu/ciberwp/92

This document has been made available through Purdue e-Pubs, a service of the Purdue University Libraries. Please contact epubs@purdue.edu for additional information. 


\title{
PATENT RACES, PRODUCT STANDARDS, AND INTERNATIONAL COMPETITION
}

\author{
Richard Jensen \\ University of Kentucky \\ Marie Thursby \\ Purdue University and NBER
}

94-015

Center for International Business Education and Research Purdue University

Krannert Graduate School of Management 1310 Krannert Building

West Lafayette, IN 47907-1310

Phone: (317) 494-4463

FAX: (317) 494-9658 
Patent Races, Product Standards, and International Competition

\author{
Richard Jensen* \\ University of Kentucky
}

Marie Thursby
Purdue University and NBER

Revised

July 1994

\begin{abstract}
We examine anticipatory product standards intended to improve the strategic position of firms in an international patent race where firms do $R \& D$ to develop products that are close substitutes. The effects of a standard are shown to depend on the way the standard is specified, which firm develops which product, and on the order in which products are discovered. Simple standards are, in general, time inconsistent because of consumer losses that occur when products ruled out by the standard are discovered before the product set as the standard. A state-contingent standard is shown to be time consistent when compulsory licensing by the foreign firm is introduced.

* The authors thank the anonymous referees, Joseph Farrell, Ward Hanson, Kala Krishna, Pierre Regibeau, Katharine Rockett, Bob Staiger and participants of the European Research Workshop on International Trade, NBER Summer Institute, 19th Telecommunications Policy Research Conference, Universities of British Columbia, Colorado, and Western Ontario, Columbia, Indiana, Wilfrid Laurier Universities, and the Catholic University of Leuven for insightful comments. Suddhasastwa Roy is thanked for research assistance. Jensen's research was made possible by a Summer Research Grant from the College of Business and Economics of the University of Kentucky. The grant was made possible by a donation of funds from Ashland Oil, Inc. Thursby's research is partially funded by the Center for the Management of Manufacturing Enterprises, Krannert Graduate School of Management.
\end{abstract}




\section{Introduction}

International R\&D competition often results in outcomes where several firms develop and patent products that are close substitutes. In this situation, it is not uncommon for governments to set anticipatory standards intended to improve the strategic (competitive) position of their firms. ${ }^{1}$ This paper examines the impact of such standards, and shows that in a dynamic, uncertain environment, the use of simple, anticipatory standards is problematic. The welfare effects of a standard are shown to depend on the way the standard is specified, but more importantly on which firm develops which product and on the order in which products are discovered. We show that simple standards are, in general, time inconsistent. Even if a standard increases welfare after all products are discovered, it still can reduce ex ante expected welfare because consumers are hurt when products ruled out by a simple standard are discovered before the discovery of the product set as the standard. Thus the only type of standard which can unambiguously increase welfare in a dynamic, uncertain environment is one that is complicated in the sense that it is state-contingent.

Understanding the effects of product standards is important because the National Competitiveness Act of 1993 and various Congressional studies (U.S. Congress, 1988 and 1992) recommend the use of standards to support U.S. industry in technology development. One example of a standard is one requiring new products to be compatible with existing ones, such as the Federal Communication Commission's regulation that HDTV transmission in the United States either be receiver-compatible or allow simulcast with existing broadcasting channels. This regulation meant that any non-compatible signal must fit into a $6-\mathrm{MH}_{\mathrm{z}}$ channel and it was generally considered to be a strategic move to improve the position of U.S. firms trying to develop HDTV, because it meant the Japanese MUSE system could not be used in the U.S. without adaptation. When the standard was announced (September 1988), the Japanese MUSE system was in working prototype and its signal did not fit into 6- $\mathrm{MH}_{\mathrm{z}}$ (Sims (1988)). Zenith was developing a

${ }^{1}$ For other aspects of standard setting and an excellent survey of needed research on the use of standards in dynamic environments see David and Greenstein (1990). 
retrocompatible version, but it was only in the theoretical stage of development and was generally considered to be inferior to the Japanese version. Hence, this regulation was, in effect, like a standard based on the product being developed domestically. The move was considered strategic because its announced intention was to alter the Japanese advantage in the race.

The United States is not alone in this type of standard setting. As is well documented by Crane (1978), Europe never adopted a single color TV standard because individual governments promoted standards to protect the interests of their firms. Hazard and Daems (1988) and Pelkmans and Beuter (1987) also make it clear that the European position on HDTV standards has the same motivation.

This paper examines the impact of standards set for strategic reasons before products are successfully developed. In order to examine such policies, it is important to model both the racing aspect of international R\&D competition and the simultaneous development of different products by rival firms. In Section 2, we present a model of uncertain $R \& D$ between a foreign and a domestic firm where the foreign firm has an advantage in developing the superior of two closely related products. Whether firms race for the same patent, pursue different patents simultaneously, or the lagging firm drops out is determined endogenously in this model. In the absence of policy, the unique subgame perfect equilibrium (SPE) involves the foreign and domestic firm simultaneously pursuing different patents if the foreign firm has a sufficiently large advantage. In this model, dropping out is never subgame perfect in the absence of policy if pursuing an alternative patent has positive expected return for the lagging firm.

In sections 3-5, we examine the impact of a national standard in one country. Two types of standards are examined: (i) an ex ante commitment to one product as the standard throughout the race and (ii) a state-contingent standard allowing adoption of a superior product as the standard once it is discovered. As shown in Section 3, the simple standard increases the likelihood of both firms racing for the product chosen as the standard. Thus, if the lagging firm is developing an . inferior product, a standard set for its benefit may induce both firms to race for the inferior product. In Section 4, we show that such a policy in the lagging firm's home market need not be 
welfare improving ex ante even if it is certain to improve welfare ex post. This is because the standard benefits the lagging (domestic) firm only after its R\&D is successful, but consumer choices are restricted once the foreign product is discovered. Hence, the simple standard can be time inconsistent in the sense that expected welfare may increase or decrease during the race even if it increases at the end of the race. ${ }^{2}$ Time consistency is shown to be a problem with a simple standard, regardless of the product chosen or potential network benefits and regardless of the impact on equilibrium strategies. The problem arises because of uncertain discovery and the fact that consumer choices are restricted once the product ruled out by the standard is discovered.

The state-contingent standard considered in Section 5 avoids this problem because it includes a contingency for the foreign product to be adopted once it is discovered The particular policy considered benefits the lagging firm, as well as consumers, because it includes a requirement that the foreign firm license its patent at a minimal fee. ${ }^{3}$ This policy is interesting in several ways. First, in equilibrium the lagging firm may drop out of the race and wait to acquire a license from the foreign firm. Second, the policy is shown to be time consistent whether or not the lagging firm drops out. That is, when licensing occurs, domestic expected welfare is higher at every date than it would be with no policy. Section 6 concludes.

Our work differs from the literature on compatibility standards in two important ways. First, we examine the impact of a standard imposed before the successful completion of R\&D. Choi (1993, 1994), Farrell and Saloner (1985 and 1986a), and Katz and Shapiro (1986a and b) examine the relation of compatibility and innovation, but they address issues related to adoption of

${ }^{2}$ If a standard is time inconsistent, the government will have an incentive to switch policies if the product ruled out by the standard is discovered first. Policy switches in such an uncertain environment are not uncommon. An example in a different setting was the FCC reversal of its decision on a color TV standard in the fifties once a superior system was developed. This particular case involved a switch in the standard from the CBS system that was not retrocompatible to the NTSC retrocompatible system developed by other domestic firms. See Hazard and Daems (1988).

${ }^{3}$ See Farrell and Shapiro (1992) on licensing requirements associated with standard setting of HDTV. 
exogenously developed technologies which are currently available. Second, we focus on international competition. Shy (1991) and Kende (1991) examine compatibility in an international context, but they also deal with currently available product innovations that are developed exogenously. In Shy's analysis, markets are perfectly competitive and innovation takes the form of consumers investing to improve the quality of existing products. Hence, his structure prevents any analysis of how standards affect market competition or potential conflicts in the interests of consumers and producers. As noted by Farrell and Shapiro (1992) in the case of HDTV, these are important aspects of standard setting in practice. Kende (1991) considers the effect of standards on firm profits, but he examines de facto standards created by licensing among firms within a country.

Kende's analysis, as well as other international treatments of standards (Copeland (1992), Crane (1979), Pelkmans \& Beuter (1978), Hazard and Daems (1988), LeCraw (1987)), have discussed their trade inhibiting effects. ${ }^{4}$ In our analysis, the simple domestic standard has this effect because it acts as a prohibitive quota. In contrast, the time-consistent contingent standard we develop does not inhibit trade and is Pareto improving compared to the simple standard. Since the contingent standard involves compulsory licensing, our results provide a counterexample to the prevailing wisdom that such licensing practices "may have adverse effects on trade."

Our work also differs from studies of patent races that have generally analyzed models in which identical firms compete for the same patent (see Reinganum (1989) for an excellent survey). One exception is the literature on sequences of races, in which firms compete for the same patent, but are not identical because the winner of the preceding race earns greater profit during the current race. Another exception is the literature on preemption and leapfrogging. Fudenberg, Gilbert, Stiglitz, and Tirole (1983, hereafter FGST) analyze several related models in which one firm has model.

${ }^{4}$ For high enough network effects, foreign producers exit the domestic market in Kende's

${ }^{5}$ This quote is from Article 40, Annex III of GATT (1991). Article 21 speaks against compulsory licensing of trademarks. 
an advantage in a race for the same patent. In one of these models the firm behind drops out of the race immediately (and the leader does R\&D until discovery). In the others, the laggard will not only stay in the race, but also may be able to leapfrog into the leadership role if the R\&D process involves two distinct stages with random discovery or if there is imperfect monitoring of the rival's R\&D effort. Lippman and McCardle (1987 and 1988) show that if the decision to do R\&D is made at discrete dates, the laggard drops out only if its rival has a large enough lead. Harris \& Vickers (1985) generalize these models by examining a race for a single patent in which a firm may have a strategic advantage for a variery of reasons. This paper contributes to this literature by showing a laggard will not drop out if it can develop a related, though inferior, patent.

Several of the issues we raise are addressed in the international trade literature. Dixit (1988 a and b), Bagwell and Staiger (1989), and Beath (1990) examine international R\&D competition in the context of patent races. Although they allow asymmetries among firms, these studies consider firms racing to develop the same product. Krishna (1988) and Yanagawa (1990) examine trade policy in the presence of compatibility issues, but they neither examine the use of standards nor explicitly consider R\&D issues. Finally, Staiger and Tabellini (1987) examine the time consistency of international trade policy, but they do not address R\&D or standards issues.

\section{A Model of Uncertain R\&D With Substitutes}

This section presents a model of uncertain $R \& D$ between a foreign and a domestic firm where the foreign firm has an advantage in developing the superior of two closely related products. In the absence of government policy, whether firms race for the same patent or simultaneously conduct $R \& D$ on different products is shown to depend on relative returns of the products and the foreign advantage in $R \& D$. The existence of equilibria in which firms develop different products, as well as the specification of one product as superior, are both important for the policy analysis. Without the former, standards are irrelevant as a strategic policy tool. When both firms race to develop the same product, any standard that restricts market access for the foreign firm does so for the domestic firm as well. The latter is important because our interest is in national standards set to 
improve the relative position of the lagging firm in an international $R \& D$ race. As with Zenith's Spectrum Compatible system and Japan Broadcasting's MUSE system, one way in which a firm can be the "laggard" is for its version of the product is inferior to its rival's. Our specification allows us to examine the welfare effects of standards in such a setting.

We consider a two country world in which a domestic and a foreign firm choose whether or not to do $R \& D$ to develop a new product $A . R \& D$ is risky because the date of discovery is stochastic, and because winning the patent for A does not prevent the development of a close, but imperfect, substitute for $\mathrm{A}$. That is, winning the patent for A does not guarantee monopoly in the standard sense because there are many close, but imperfect, substitutes for A which are different from the view of patent law. This precludes either firm from attempting to develop all products, simultaneously or sequentially, in order to preempt or exclude the other firm from the market (see Gilbert and Newbery (1982) for a thorough discussion of this possibility). Thus, we simply assume each firm can also do R\&D to develop one of the products which are substitutes for $A$. We label this product $B$, and we assume $A$ is superior to $B$ in that each firm would prefer to win the patent for A.

Formally, we consider the following continuous time game. At each point in time (date) before either $A$ or $B$ is discovered, each firm can either do R\&D on $A$, do $R \& D$ on $B$, or do nothing. If a firm succeeds in developing A or B first, then the game essentially ends for that firm. At each date thereafter, it produces the product it discovered. The remaining firm can then either do $\mathrm{R} \& \mathrm{D}$ on the undiscovered product or do nothing at each date after this first discovery date. If this firm succeeds in developing the other product, then it produces that product at each date thereafter. To formalize our assumptions on $A$ and $B$, let $\pi_{i}(A)=\sum_{m=1}^{2} \pi_{i}^{m}(A), i=1,2$, be the total flow profit earned by firm $i$ if it has discovered $A$ but $B$ has not been discovered, where $\pi_{i}^{m}$ is firm i's flow profit from country $m$. Let $\pi_{i}(A ; B)=\sum_{m=1}^{2} \pi_{i}^{m}(A ; B)$ be the flow profit earned by firm $i$ if it has discovered $A$ and $B$ has been discovered. Define $\pi_{i}(B)$ and $\pi_{i}(B ; A)$ analogously. Then $\pi_{i}^{m}(A)>\pi_{i}^{m}(A ; B)$ and $\pi_{i}^{m}(B)>\pi_{i}^{m}(B ; A)$ embody the notion that $A$ and $B$ are substitutes, 
and $\pi_{i}^{m}(A)>\pi_{i}^{m}(B)$ and $\pi_{i}^{m}(A ; B)>\pi_{i}^{m}(B ; A)$ imply $A$ is superior to $B$ in each market. Thus, we assume for $m=1,2$ that

$$
\pi_{i}^{m}(A)>\max \left\{\pi_{i}^{m}(B), \pi_{i}^{m}(A ; B)\right\} \text { and } \pi_{i}^{m}(B ; A)<\min \left\{\pi_{i}^{m}(B), \pi_{i}^{m}(A ; B)\right\},
$$

which guarantees the expected return from discovering $\mathrm{A}$ is greater than that from discovering $\mathrm{B}$ when the $R \& D$ costs of $A$ and $B$ are the same. Also note this does not assume $A$ is superior enough to $B$ in production that $\pi_{i}^{m}(A ; B)>\pi_{i}^{m}(B)$. That is, having a monopoly with $B$ in each market may provide greater profit than producing $A$ when $B$ is available. This profit ranking can hold with a variety of differentiated product models, including Shaked and Sutton's (1982) vertically differentiated demand structure and models with network externalities and variety (Farrell and Saloner (1986b)). We demonstrate this for the Shaked and Sutton case in Appendix 2.

The discovery date of each new product is assumed to be stochastic and exponentially distributed with parameter $\mu$, so that if either firm does $R \& D$, the probability it will discover the new product between times $t$ and $t+d t$ is $\mu d t$. Firms incur a constant flow cost of development, and these costs may differ by firm as well as the product being developed. Firm i must pay a constant flow cost $k_{\mathrm{iA}}>0$ to do $R \& D$ on $A$ or a constant flow cost $k_{i B}>0$ to do $R \& D$ on $B$ $(i=1,2)$. Then firm $i$ has an advantage relative to firm $j$ in developing $A$ if $k_{i A}<k_{j A} j \neq i$. Under (A1) and our specification of $R \& D$, this is the most tractable way to represent one firm as having an advantage in the race. As will be clear from Theorem 1, the asymmetry in firm costs is necessary for the existence of a unique equilibrium in which the domestic and foreign firm conduct $R \& D$ on different products. The asymmetry in the cost to develop each product seems natural for vertically differentiated products. Moreover, given (A1), B would never be the first product developed if $k_{\mathrm{iA}}=k_{\mathrm{iB}}$, for $\mathrm{i}=1,2$. Also note, this modeling choice is not crucial because the analysis can be generalized to hazard rates that differ among firms or innovations, or that depend on accumulated R\&D experience, as in FGST (1983) and Lippman and McCardle (1988).

Because we are interested in the subgame perfect equilibria (SPE), we must construct payoffs which incorporate optimal behavior by the remaining firm after its rival has discovered A 
or B. Suppose that firm $i$ discovers A first. If firm $j(j=1,2 j \neq i)$ does R\&D on B at every date until it succeeds, then it pays the flow cost $k_{j B}$ until $B$ is discovered and earns the flow profit $\pi_{\mathrm{j}}(\mathrm{B} ; \mathrm{A})$ thereafter. Hence, the expected return from $R \& D$ on $B$ at every date until discovery, discounted back to the discovery date of $\mathrm{A}$ is

$$
S_{j B}=\left[(\mu / r) \pi_{j}(B ; A)-k_{j B}\right] /(r+\mu)
$$

where $S_{j B}$ is. used to denote the fact that $B$ is the second product discovered (by $j$ ) and $r$ is the common discount rate. Note that the assumption

$$
(\mu / r) \pi_{j}^{m}(B ; A)>k_{j B} \text { for } j, m=1,2
$$

guarantees that, given A has been discovered, firm j's optimal strategy is to do R\&D on B at every date thereafter until it succeeds.

Similarly, firm i earns $\pi_{i}(A)$ in each period after $A$ is discovered, but before $B$ is discovered, and $\pi_{\mathrm{i}}(\mathrm{A} ; \mathrm{B})$ in each period after $\mathrm{B}$ is discovered. Hence, firm i's expected return from $A$, discounted back to its discovery date, is

$$
F_{i A}=\left[\pi_{i}(A)+(\mu / r) \pi_{i}(A ; B)\right] /(r+\mu) .
$$

The notation $F_{i A}$ denotes that $A$ is the first product discovered (by $i$ ).

Now suppose firm $i$ discovers $B$ first. If firm $j$ does $R \& D$ on $A$ at every date until it succeeds, its expected return discounted back to the discovery date of B is

$$
S_{j A}=\left[(\mu / r) \pi_{j}(A ; B)-k_{j A}\right] /(r+\mu) .
$$

The assumption

$$
(\mu / \mathrm{r}) \pi_{\mathrm{j}}^{\mathrm{m}}(\mathrm{A} ; \mathrm{B})>\mathrm{k}_{\mathrm{jA}} \text { for } \mathrm{j}, \mathrm{m}=1,2
$$

guarantees that, given B has been discovered, firm j's optimal strategy is to do R\&D on A at every date thereafter until it succeeds. In the absence of standards, (A2) and (A3) are stronger than is necessary to ensure that the expected return to $R \& D$ on each good is positive, even when the other product is available. We prefer to make these strong assumptions, however, because they ensure a positive expected return to $R \& D$ on both products even when market access is denied by a standard in one market. As noted above, (A1) implies $S_{j A}>S_{j B}$ if $k_{j B}=k_{j A}$ (superiority of $A$ in production 
implies its superiority in development if the flow costs are the same). Firm i's expected return from B, discounted back to its discovery date, is

$$
F_{\mathrm{iB}}=\left[\pi_{\mathrm{i}}(\mathrm{B})+(\mu / \mathrm{r}) \pi_{\mathrm{i}}(\mathrm{B} ; \mathrm{A})\right] /(\mathrm{r}+\mu) .
$$

Notice (A1) also implies $F_{\mathrm{iA}}>\mathrm{F}_{\mathrm{iB}}$. More importantly, there is an incentive for a firm at a disadvantage in a race for $A$ to begin trying to develop $B$ immediately, rather than race for $A$ and develop B if it loses the race. If it discovers B first, it earns monopoly profit $\pi_{\mathrm{i}}(\mathrm{B})$ until $\mathrm{A}$ is discovered.

Now consider the game before A or B has been discovered (which is assumed to begin at $\mathrm{t}=0$ ). Let a denote the strategy of doing $\mathrm{R} \& \mathrm{D}$ on $\mathrm{A}$ at every date until its discovery by either firm, and then continuing optimally (as noted above). Similarly, let b denote the strategy of doing R\&D on $B$ at every date until its discovery by either firm, and then continuing optimally. Let $d$ denote delaying, the strategy of doing nothing at every date until either product is discovered by the other firm, and then continuing optimally. The memorylessness property of the exponential distribution and the assumption of a constant hazard rate allows the payoffs from these strategies to be written simply in reduced form. Table 1 gives the expected payoffs to firm 1 for all possible choices of these strategies by itself and firm 2 . The payoffs to firm 2 are omitted because they are defined analogously.

It is easy to see from these payoffs that delaying $R \& D$ cannot be an equilibrium in this model. ${ }^{6}$ This is because (A2) and (A3) ensure that a firm's expected return to doing R\&D on either $A$ or $B$ is greater than the return to delaying, regardless of its rival's strategy. As long as discovering either product has a positive expected return, then it is surely better for a firm to begin $R \& D$ immediately because there is a chance it will discover its product first. Therefore the only question is whether a firm conducts $R \& D$ on $A$ or $B$. From Table 1, one can see that $\mu\left(F_{1 A}-F_{1 B}\right)$

${ }^{6}$ Delaying can be an equilibrium in certain policy scenarios, such as that considered in Section 5. It can also be an equilibrium when there are spillovers or if imitation is possible. It is also possible for $(\mathrm{a}, \mathrm{b})$ to be an equilibrium with spillovers (or imitation) because a firm earns monopoly profits for some period if it discovers its product first. Results for the race with spillovers are available from the authors. 
$>k_{1 \mathrm{~A}}-\mathrm{k}_{1 \mathrm{~B}}$ implies that firm 1 will do R\&D on A regardless of firm 2's strategy. This condition simply says that firm 1's expected flow return from being first to discover A, net of the flow cost of $R \& D$, is greater than that from being first to discover B. Conversely, if $\mu\left(F_{1 A}-F_{1 B}\right)<$ $k_{1 A}-k_{1 B}$, then firm 1's expected flow return from being first to discover $B$ (net of the flow cost of $R \& D)$ exceeds that from $A$, and firm 1 will do $R \& D$ on $B$ regardless of firm 2's strategy. Analogous arguments apply to firm 2, so that the results of Theorem 1 follow immediately. Formal proofs of this theorem and all remaining ones in the paper, are given in Appendix 1.

\section{Theorem 1. Under (A1)-(A3), the unique subgame perfect equilibrium is:}

(i) (a,a) if and only if $k_{i A}-k_{i B}<\mu\left(F_{i A}-F_{i B}\right)$ for $i=1,2$.

(ii) (a,b) if and only if both $k_{1 A}-k_{1 B}<\mu\left(F_{1 A}-F_{1 B}\right)$ and $k_{2 A}-k_{2 B}>\mu\left(F_{2 A}-F_{2 B}\right)$.

(iii) $(b, a)$ if and only if both $k_{1 A}-k_{1 B}>\mu\left(F_{1 A}-F_{1 B}\right)$ and $k_{2 A}-k_{2 B}<\mu\left(F_{2 A}-F_{2 B}\right)$.

(iv) $(b, b)$ if and only if $k_{i A}-k_{i B}>\mu\left(F_{i A}-F_{i B}\right)$ for $i=1,2$.

Figure 1 is a convenient way to describe the results in Theorem 1 . The lines $\mu\left(F_{1 A}-F_{1 B}\right)=k_{1 A}-k_{1 B}$ and $\mu\left(F_{2 A}-F_{2 B}\right)=k_{2 A}-k_{2 B}$ divide the space into four quadrants, where equilibria are as indicated. These lines intersect at $I$, where $k_{\mathrm{iA}}-\mathrm{k}_{\mathrm{iB}}>0$ for both $\mathrm{i}$, because (A1) implies that it is better to be first to develop $A$ than $B, F_{i A}>F_{i B}$. Notice that the equilibrium of this game is unique for all values of parameters such that $k_{i A}-k_{i B} \neq \mu\left(F_{i A}-F_{i B}\right)$ for both $i=1,2$. The reason for this is that a is firm i's strongly dominant strategy if and only if $k_{i A}-k_{i B}<\mu\left(F_{i A}-F_{i B}\right)$, and $b$ is firm i's strongly dominant strategy if and only if $k_{i A}-k_{i B}>\mu\left(F_{i A}-F_{i B}\right)$.

If, however, $k_{i A}-k_{i B}=\mu\left(F_{i A}-F_{i B}\right)$ for either or both firms, then there are multiple SPE. For example, if $k_{1 A}-k_{1 B}=\mu\left(F_{1 A}-F_{1 B}\right)$ and $k_{2 A}-k_{2 B}>\mu\left(F_{2 A}-F_{2 B}\right)$, then $(a, b)$ is still an SPE, but there is a continuum of other SPE. One of these is firm 2 does $R \& D$ on $B$ at every date until its discovery, but firm 1 switches between $R \& D$ on $A$ and $R \& D$ on $B$ at every date until one of them is discovered. Although this type of result is interesting, in general, we do not dwell upon this possibility. The focus of our analysis is on the outcome where, absent policy, the firms would simultaneously develop different products. 
As is clear from Figure 1, whether or not one firm has an advantage over the other in developing a product depends on the flow costs of R\&D. The easiest way to see this is to observe that, if flow $R \& D$ costs are the same for both firms and products, then $k_{1 A}-k_{1 B}=k_{2 A}-k_{2 B}=0$. The corresponding point in the figure is the origin, and $(a, a)$ is the unique SPE. However, if firm 1 is given a large enough advantage in developing $A$ (by increasing $k_{2 A}$ enough), then the point $\left(k_{1 A}-k_{1 B}, k_{2 A}-k_{2 B}\right)$ in the figure moves upward along the $k_{2 A}-k_{2 B}$ axis until $(a, b)$ is the unique SPE. The latter equilibrium is the most interesting one for our purposes. Not only is it consistent with the observation that firms often race to develop imperfect substitutes, but also it allows us to examine the impact of product standards announced before products are developed.

\section{R\&D Under a National Standard}

In this section, we examine $R \& D$ decisions in the presence of a national standard in one country. We define a standard set by country m's government as a product specification that must be met in order for the product to be sold in country $m, m=1,2$. If, for example, $B$ is set as a standard in country $\mathrm{m}$, any product sold by either firm in that market must have the same characteristics as B. The only way A can be sold in country $\mathrm{m}$, is for an adapter to be developed so that A meets the same specification as B. In reality, standards may be specified in terms of single characteristics (such as band width), or governments may announce the product developed by a domestic firm "as the standard." The former is consistent with FCC policy in 1988, and the latter was characteristic of European standard setting with color TV. Our definition of a standard can be consistent with both examples and is a simple way of introducing standards to the analysis.

In this setting, a standard in country m creates monopoly power in the m's market for the firm that develops the product chosen as the standard. Since this reduces the expected return to either firm from developing the other product, both firms are more likely to develop the product chosen as the standard. Formally, let the superscript $p=a, b$ denote a variable when there is a standard in country $\mathrm{m}$. Suppose A is the standard. Because B cannot be sold in $\mathrm{m}$, firm i's flow profit from selling B comes entirely from sales in the other country, $n$. That is, 
$\pi_{i}^{a}(B)=\pi_{i}^{n}(B)<\pi_{i}(B)$ for $i=1,2$ and $n \neq m$ before the successful completion of the rival's $\mathrm{R} \& \mathrm{D}$ and $\pi_{\mathrm{i}}^{\mathrm{a}}(\mathrm{B} ; \mathrm{A})=\pi_{i}^{\mathrm{n}}(\mathrm{B} ; \mathrm{A})<\pi_{\mathrm{i}}(\mathrm{B} ; \mathrm{A})$ once $\mathrm{A}$ has been developed. As long as country n's government is inactive, $\pi_{\mathrm{i}}^{2}(\mathrm{~A})=\pi_{\mathrm{i}}(\mathrm{A})$ because $\mathrm{A}$ can be sold in each market. The flow profit from $A$ when $B$ is available increases under this policy because the firm selling $A$ in country $m$ earns monopoly profit in that market. That is, $\pi_{i}^{a}(A ; B)=\pi_{i}^{n}(A ; B)+\pi_{i}^{m}(A)>\pi_{i}(A ; B)$. This implies $F_{i A}^{2}>F_{i A}$ and $F_{i B}^{a}<F_{i B}$ for both firms. Although it also implies $S_{i A}^{2}>S_{i A}$ and $S_{i B}^{2}<S_{i B}$, (A2) and (A3) are sufficient for both goods to be developed. The impact of B as a standard in country $m$ is analogous.

Theorem 2. Let $S=[-M, M] X[-M, M]$ be the set of all feasible values of $\mathrm{k}_{1 \mathrm{~A}}-\mathrm{k}_{1 \mathrm{~B}}$ and $\mathrm{k}_{2 \mathrm{~A}}-\mathrm{k}_{2 \mathrm{~B}}$, where $M$ is a positive number large enough to bound $\mu\left(\mathrm{F}_{\mathrm{iA}}-\mathrm{F}_{\mathrm{iB}}\right)$ and $\mu\left(\mathrm{F}_{\mathrm{iA}}^{\mathrm{P}}-\mathrm{F}_{\mathrm{iB}}^{\mathrm{P}}\right)$ in absolute value for $i=1,2$ and $p=a, b$. Then the imposition of a national standard by either government increases the likelihood that both firms race to develop the product chosen as the standard (i.e., increases the area of the set of parameters for which the firms racing is the unique $S P E)$.

To consider the implications of Theorem 2 for strategic standard setting, assume firms 1 and 2 are owned by residents of countries 1 and 2, respectively, and that firm 1's advantage in developing $A$ is large enough that $(a, b)$ is the unique SPE in the absence of policy. Since firm 2 is the "laggard," the policy of interest is an ex ante commitment by country 2 's government to B as a standard. With this policy, the government ensures monopoly profits at home for the domestic firm if it is first to develop its product. While this increases the domestic firm's expected return from developing B, it does so for the foreign firm as well. Thus, as shown in Figure 2a, the lines denoting equality of expected relative returns and relative $R \& D$ costs shift toward the axes. The area to the northeast of I' represents parameter values for which $(b, b)$ is the unique equilibrium with the standard. This area is clearly larger than the area northeast of I, which represents parameter values for which $(b, b)$ is the unique equilibrium without policy.

Thus with uncertain $\mathrm{R} \& \mathrm{D}$, ex ante commitment to $\mathrm{B}$ as a standard may not benefit the domestic firm. The foreign firm is the beneficiary, ex post, if the standard induces firm 1 to 
conduct $R \& D$ on $B$ and firm 1 wins the race. Of course, if firm 2 wins the race or if $(a, b)$ remains the equilibrium, the domestic firm benefits ex post. If, for example, $\mathrm{G}$ represents relative flow costs, neither firm's equilibrium strategy is altered and the standard acts as a prohibitive quota once both products are developed. ${ }^{7}$

These effects are in sharp contrast to those of an R\&D subsidy designed to improve firm 2's position. Since firm 2's disadvantage is a flow cost for developing A that is higher than firm 1 's, the subsidy that reduces (or potentially eliminates) its disadvantage is a constant for each date the firm does $R \& D$ on $A$. Let $z_{2 A}$ represent this subsidy. With the subsidy, firm 2's equilibrium strategy depends on $\mu\left(\mathrm{F}_{2 A}-\mathrm{F}_{2 \mathrm{~B}}\right)$ relative to $\mathrm{k}_{2 \mathrm{~A}}-\mathrm{z}_{2 \mathrm{~A}}-\mathrm{k}_{2 \mathrm{~B}}$. It is then straightforward to show that the subsidy increases the likelihood of a unique equilibrium in which firm 2 attempts to develop A. Firm 1's strategy is unaffected since its expected profit is the same as with no policy. Thus the subsidy shifts only the horizontal reference line in Figure $2 b$. When $z_{2 A}$ is available to firm 2, $(a, b)$ is the unique equilibrium for parameter values to the northwest of $I^{\prime \prime}$, and $(b, b)$ is the unique equilibrium to the northeast of I". This area is clearly smaller than the area north of.$^{8}$

Thus, while the subsidy and standard are both designed to benefit firm 2 , their effects are quite different. In part, this is because the subsidy is firm specific, and the standard is market specific, altering both firms' incentives. In addition, the standard and subsidy analyzed here alter firm 2's incentives in opposite directions. B as a standard reinforces the domestic firm's decision in the absence of a standard, a decision directly related to the cost disadvantage. By reducing the cost disadvantage, the subsidy reduces firm 2's incentive to develop B. Finally, the subsidy has no effect on market access, while the standard acts as a prohibitive quota, ensuring a monopoly market for the firm that wins the race for $B$. This, of course, raises questions as to consumer

${ }^{7}$ It is straightforward to show that the probability any point $\mathrm{G}$, to the northwest of $\mathrm{I}$, is also to the northwest of I', decreases with the size of country 2's market and the hazard rate. In the case of HDTV and the FCC regulation, some analysts predicted the Japanese would not find it worthwhile to modify their development strategy.

8If, however, the $R \& D$ programs are subsidized equally (i.e., $z_{2 A}=z_{2 B}$ ), neither reference line shifts and the equilibrium outcomes are the same as in the game with no policy. If only $R \& D$ on $B$ is subsidized, the set of parameter values for which $(a, b)$ and $(b, b)$ is the unique equilibrium is larger with the subsidy. 
effects of the standard. In the next section, we show that the quota-like characteristic of a standard can be problematic, even when network benefits of the standard are important.

Before proceeding, note that Theorem 2 implies $\mathrm{A}$ as a standard affects firm 2 's incentives in the same direction as $z_{2 A}$. Thus $A$ is the standard that offsets firm 2 's disadvantage. This type of policy is uncommon, however, because it involves an ex ante commitment by country 2 's government to the product being developed by the foreign firm. ${ }^{9}$ Note also that our analysis presumes an adapter cannot be developed to bring $\mathrm{A}$ in line with the standard. If an adapter could be developed, which would not increase A's production cost, then the standard would have no effect. If an adapter could be developed, but was costly to produce, then the standard would have the same qualitative effects as it does in Theorem 2.

\section{Welfare Effects of $B$ as a Standard}

A major concern with standards set for strategic reasons is their impact on consumers, and hence aggregate welfare. This is a natural concern for the type of race we consider, not only because a standard limits market access, but also because an inferior product may be chosen if the standard is set to benefit the lagging firm. "Lock in" to an inferior technology (or product) is a well known problem with de facto standardization with network effects and with de jure standardization in dynamic models with private information and learning. ${ }^{10}$ Here we show that de jure standardization can be problematic even if the only uncertainty is the arrival dates of products and with or without significant network effects.

In this section we examine the welfare effects of an ex ante commitment by country 2 's government to B as a standard. Whether the standard increases welfare in country 2 throughout the race is shown to depend on consumer surplus effects, as well as the order in which products are discovered. We show that even if the standard increases welfare at the end of the game, it can

${ }^{9}$ An exception is post World War II Japanese policy in machine tools, which involved support of domestic firms if they produced according to foreign standards.

${ }^{10}$ For examples, see David and Greenstein (1990), Lehr (1994), and Choi (1993). 
be time inconsistent in the sense that expected welfare at the beginning of the game may not increase. That is, in a game where the government moves first, applying a standard uniformly throughout the game would not be a subgame perfect equilibrium.

For simplicity, we assume parameter values are such that $(a, b)$ is the unique equilibrium with and without the standard; that is,

$$
\mathrm{k}_{1 \mathrm{~A}}-\mathrm{k}_{1 \mathrm{~B}}<\mu\left(\mathrm{F}_{1 \mathrm{~A}}^{\mathrm{b}}-\mathrm{F}_{1 \mathrm{~B}}^{\mathrm{b}}\right) \text { and } \mathrm{k}_{2 \mathrm{~A}}-\mathrm{k}_{2 \mathrm{~B}}>\mu\left(\mathrm{F}_{2 \mathrm{~A}}-\mathrm{F}_{2 \mathrm{~B}}\right) \text {. }
$$

In this case, firm 2 clearly benefits from the standard once both $A$ and $B$ are discovered, so that whether or not country 2's welfare increases depends on consumer surplus effects. Neither this assumption, nor our focus on B as the standard, is critical since the time consistency problem we examine also occurs if $(b, b)$ is the unique equilibrium with $B$ as the standard or if $A$ is the standard imposed in country 2 .

There are three times at which it is natural to compare welfare; the beginning of the game $(\mathrm{t}=0)$; the first discovery date; and the second discovery date (i.e., when both have been discovered). Suppose firm 1 succeeds first. Then in the absence of policy, expected welfare, discounted back to the discovery date of $\mathrm{A}$, in each country is

$$
\begin{aligned}
& \mathrm{W}_{1}\left(\mathrm{~F}_{1 \mathrm{~A}}\right)=\left\{\pi_{1}(\mathrm{~A})+\mathrm{C}_{1}(\mathrm{~A})+(\mu / \mathrm{r})\left[\pi_{1}(\mathrm{~A} ; \mathrm{B})+\mathrm{C}_{1}(\mathrm{~A}, \mathrm{~B})\right]\right\} /(\mathrm{r}+\mu) \text { and } \\
& \mathrm{W}_{2}\left(\mathrm{~S}_{2 \mathrm{~B}}\right)=\left\{\mathrm{C}_{2}(\mathrm{~A})+(\mu / \mathrm{r})\left[\pi_{2}(\mathrm{~B} ; \mathrm{A})+\mathrm{C}_{2}(\mathrm{~A}, \mathrm{~B})\right]-\mathrm{k}_{2 \mathrm{~B}}\right\} /(\mathrm{r}+\mu)
\end{aligned}
$$

where flow consumer surplus in country $i$ is $C_{i}(A)$ if only $A$ is available and $C_{i}(A, B)$ if both $A$ and B are available. Similarly, if firm 2 succeeds first, then expected welfare, discounted back to the discovery date of $B$, in each country is

$$
\begin{aligned}
& \mathrm{W}_{1}\left(\mathrm{~S}_{1 \mathrm{~A}}\right)=\left\{\mathrm{C}_{1}(\mathrm{~B})+(\mu / \mathrm{r})\left[\pi_{1}(\mathrm{~A} ; \mathrm{B})+\mathrm{C}_{1}(\mathrm{~A}, \mathrm{~B})\right]-\mathrm{k}_{1 \mathrm{~A}}\right\} /(\mathrm{r}+\mu) \text { and } \\
& \mathrm{W}_{2}\left(\mathrm{~F}_{2 \mathrm{~B}}\right)=\left\{\pi_{2}(\mathrm{~B})+\mathrm{C}_{2}(\mathrm{~B})+(\mu / \mathrm{r})\left[\pi_{2}(\mathrm{~B} ; \mathrm{A})+\mathrm{C}_{2}(\mathrm{~A}, \mathrm{~B})\right]\right\} /(\mathrm{r}+\mu)
\end{aligned}
$$

where $C_{i}(B)$ is flow consumer surplus if only $B$ is available. Initial expected welfare (at $t=0)$ is defined analogously to the expected firm payoffs; that is,

$$
\begin{aligned}
& \left.\mathrm{W}_{1}(\mathrm{a}, \mathrm{b})=\left[\mu \mathrm{W}_{1}\left(\mathrm{~F}_{1 \mathrm{~A}}\right)+\mu \mathrm{W}_{1}\left(\mathrm{~S}_{1 \mathrm{~A}}\right)-\mathrm{k}_{1 \mathrm{~A}}\right)\right] /(\mathrm{r}+2 \mu) \text { and } \\
& \left.\mathrm{W}_{2}(\mathrm{a}, \mathrm{b})=\left[\mu \mathrm{W}_{2}\left(\mathrm{~F}_{2 \mathrm{~B}}\right)+\mu \mathrm{W}_{2}\left(\mathrm{~S}_{2 \mathrm{~B}}\right)-\mathrm{k}_{2 \mathrm{~B}}\right)\right] /(\mathrm{r}+2 \mu) .
\end{aligned}
$$


Expressions for expected welfare under the standard are defined analogously to (6)-(11) with $\pi_{i}^{\mathrm{b}}$ $(\bullet)$ and $\mathrm{C}_{\mathrm{i}}^{\mathrm{b}}(\cdot)$ replacing $\pi_{\mathrm{i}}(\cdot)$ and $\mathrm{C}_{\mathrm{i}}(\bullet)$.

Under our assumptions it is clear that the standard reduces welfare in country 1 at all three dates because it decreases firm 1's profit, and consumers are either unaffected or their welfare declines in the presence of network effects. However, the effect of the standard on country 2's welfare is ambiguous. Firm 2 must gain after both $A$ and $B$ are discovered, of course, because it has a monopoly in its own market, $\pi_{2}^{b}(B ; A)>\pi_{2}(B ; A)$. Whether consumers gain or lose after both $\mathrm{A}$ and $\mathrm{B}$ are discovered depends on the magnitude of the benefits from network externalities, if any. Without network effects, domestic monopoly provision of $\mathrm{B}$ implies consumers must lose, $C_{2}^{b}(A, B)=C_{2}^{b}(B)=C_{2}(B)<C_{2}(A, B)$. But with network effects, consumers may well prefer monopoly provision of $B$ to duopoly provision of $A$ and $B, C_{2}(B)>C_{2}(A, B)$. Thus we have two cases to consider. In the first, monopoly effects dominate any network benefits,

$$
\mathrm{C}_{2}(\mathrm{~A}, \mathrm{~B})>\mathrm{C}_{2}(\mathrm{~A})>\mathrm{C}_{2}(\mathrm{~B}) \text {, }
$$

so flow welfare increases after both A and B are discovered only if firm 2's gain exceeds consumers' losses, $\pi_{2}^{\mathrm{b}}(\mathrm{B} ; \mathrm{A})-\pi_{2}(\mathrm{~B} ; \mathrm{A})>\mathrm{C}_{2}(\mathrm{~A}, \mathrm{~B})-\mathrm{C}_{2}(\mathrm{~B})$. In the second, network benefits dominate,

$$
\mathrm{C}_{2}(\mathrm{~A})>\mathrm{C}_{2}(\mathrm{~B})>\mathrm{C}_{2}(\mathrm{~A}, \mathrm{~B}) \text {, }
$$

so flow welfare must increase, $\pi_{2}^{b}(B ; A)+C_{2}(B)>\pi_{2}(B ; A)+C_{2}(A, B)$.

Even if the standard increases flow welfare after both $A$ and $B$ are discovered, however, it need not increase expected welfare either at the beginning of the game or at the first discovery date. If $\mathrm{A}$ is discovered first, then consumers lose between the discovery dates of $\mathrm{A}$ and $\mathrm{B}$ because the standard acts as a prohibitive quota on $A, C_{2}^{b}(A)=0<C_{2}(A)$. Under both (A4) and (A5), it is this interim loss to consumers that leads to time consistency problems with the standard. Theorem 3 describes when $B$ as a standard is time-consistent or not.

Theorem 3: Assume (5) holds. If the standard reduces country 2's flow welfare after both $A$ and $B$ are discovered, it also reduces both initial expected welfare and expected welfare at the first discovery date whether $A$ or $B$ is discovered first. 
If the standard increases flow welfare after both $A$ and $B$ are discovered, it will also increase both initial expected welfare and expected welfare at the first discovery date if

$$
\mathrm{C}_{2}(\mathrm{~A})<(\mu / \mathrm{r})\left[\pi_{2}^{2}(\mathrm{~B})-\pi_{2}^{2}(\mathrm{~B} ; \mathrm{A})+\mathrm{C}_{2}(B)-\mathrm{C}_{2}(\mathrm{~A}, \mathrm{~B})\right] \text {. If, however, }
$$$$
0<(\mu / \mathrm{r})\left[\pi_{2}^{2}(\mathrm{~B})-\pi_{2}^{2}(\mathrm{~B} ; \mathrm{A})+\mathrm{C}_{2}(\mathrm{~B})-\mathrm{C}_{2}(\mathrm{~A}, \mathrm{~B})\right] \leq \mathrm{C}_{2}(\mathrm{~A}) \text { the standard can be time }
$$
inconsistent in three ways:

(iii) It can increase initial expected welfare, decrease expected welfare at the first discovery date if $A$ is discovered first, and then increase flow welfare after $B$ is also discovered.

(iv) It can decrease initial expected welfare, decrease expected welfare at the first discovery date if $A$ is discovered first, and increase flow welfare after $B$ is also discovered.

(v) Finally, it can decrease initial expected welfare, increase expected welfare at the first discovery date if $B$ is discovered first, and then increase flow welfare after $A$ is also discovered.

If the standard reduces welfare in country 2 after $A$ and B are discovered, $\pi_{2}^{b}(B ; A)+C_{2}(B)<\pi_{2}(B ; A)+C_{2}(A, B)$, then expected welfare at the first discovery date is also lower whether $A$ or $B$ is discovered first, $W_{2}\left(F_{2 B}^{b}\right)<W_{2}\left(F_{2 B}\right)$ and $W_{2}\left(S_{2 B}^{b}\right)<W_{2}\left(S_{2 B}\right)$. Therefore initial expected welfare is lower under this standard, $W_{2}^{b}(a, b)<W_{2}(a, b)$. If instead, the standard increases flow welfare in country 2 after both $\mathrm{A}$ and $\mathrm{B}$ are discovered, the right hand side of (i) in Theorem 3 is positive. Notice the right hand side of (i) is always positive under (A5), and it is positive under (A4) if the gain to firm 2 outweighs the loss to consumers. In either case, if $B$ is discovered first, this positive term represents the only effect of the standard. If, however, $\mathrm{A}$ is discovered first, some consumers lose because they cannot consume $\mathrm{A}$ in the interim (even if they are stranded once B is discovered). This interim loss is represented by the left hand side of (i). If this loss is small enough for (i) to hold, the standard is time consistent. If, however, (ii) holds, the standard can increase or decrease expected welfare at the first discovery date when $\mathrm{A}$ is discovered first, and so increase or decrease intitial expected welfare even though flow welfare increases at the end of the game. The intuition is simply that the standard hurts consumers after $\mathrm{A}$ is discovered, but helps firm 2 only after both products are discovered. If $B$ is discovered first, then the only 
effect occurs after both have been discovered, when welfare is higher with the standard.

Consumers' expected loss between the discovery times of $\mathrm{A}$ and $\mathrm{B}$ may be large enough to outweigh the flow welfare increase after B is discovered,which gives rise to cases (iii) - (v) above.

The results in Theorem 3 are based on the assumption that $(a, b)$ is the unique equilibrium with or without $B$ as a standard. To see that this assumption is not critical, suppose $(b, b)$ becomes the unique equilibrium with $B$ as the standard in country 2 . If firm 2 wins the race for $B$, then firm 1's only recourse is to develop A, and the welfare effects are exactly the same as those when $(a, b)$ is the SPE and firm 2 discovers B first. That is, the standard is time consistent under condition (i) in Theorem 3. If firm 1 wins the race for $B$, however, then it is easy to see that the standard is not time consistent after firm 2 discovers A. When monopoly effects dominate, (A4), one would expect country 2's government to drop the standard because it reduces both consumer surplus and profit, $C_{2}(B)<C_{2}(A, B)$ and $\pi_{2}^{b}(A ; B)<\pi_{2}(A ; B)$. When network effects dominate, (A5), one would expect country 2's government to switch and set A as the standard because this increases consumer surplus and firm 2's profit, $C_{2}(A)>C_{2}(B)$ and $\pi_{2}^{1}(A ; B)+\pi_{2}^{2}(A)>$ $\pi_{2}(\mathrm{~A} ; \mathrm{B})$.

Similar problems arise if $\mathrm{A}$ is the standard. As is clear from Theorem 2, $(\mathrm{a}, \mathrm{a})$ is more likely to be the unique equilibrium in this case. With uncertain R\&D it is not clear that firm 2 will win the race or that welfare will improve. Moreover, firm 2 may have enough of a disadvantage in $R \& D$ on $A$ that $(a, b)$ remains the equilibrium, in which case firm 2 loses since it can't sell $B$ in its own market (without an adapter). With or without network effects, consumers lose between the first and second discovery dates, if $B$ is discovered first, because they cannot consume the product. As before, consumer effects depend on the net effects of monopoly and networks. 


\section{Toward a Time-Consistent Standard}

The results of Section 4 suggest that anticipatory standards can be problematic, regardless of which standard is set. The results are driven by uncertain discovery and the fact that either standard acts as a prohibitive quota once the foreign product is discovered. In this section, we show that a contingent standard with a compulsory license clause can circumvent these problems.

We consider the following state-contingent policy: (i) A is the standard in country 2 if it is discovered by firm 2 or if firm 1 discovers it and licenses the patent to firm 2 at a fixed fee (set by the government); (ii) B is set as a standard once it is discovered if firm 1 discovers A, but does not license the patent. This policy satisfies the strategic motive to improve firm 2 's competitive position in the race because it benefits firm 2 regardless of which product is discovered first. Interestingly, however, it may induce firm 2 to exit the race if the potential gain from licensing is high enough. As we show in this section, it also benefits consumers in country 2 (relative to any of the situations considered in Section 4) because of duopoly competition when licensing occurs.

For clarity we focus on the case where $(a, b)$ is the unique SPE in the absence of policy and if $\mathrm{B}$ is the standard. We prove the contingent policy outlined above is time consistent under (A5). We prove it is also time-consistent under (A4) if the standard benefits firm 2 more than it hurts consumers in country 2 once both products are discovered. ${ }^{11}$ Eliminating the case where consumers lose more than firm 2 gains under (A4) entails no loss of generality since B as a standard is time consistent in that case. Time inconsistency arises in the other case because, even though the standard increases flow welfare after both products are discovered, consumers in country 2 lose after $A$ is discovered, but firm 2 gains only after $B$ is discovered. Therefore, a time consistent policy must have the property that both firm 2 and consumers in country 2 benefit from it whichever product is discovered first.

${ }^{11}$ If $B$ as a standard reduces welfare after both products are discovered, it is not a credible policy for country 2's government. This lack of credibility alters the expected returns to firms 1 and 2 so that licensing is unlikely to occur in equilibrium. Thus the benefits associated with licensing under the contingent policy we consider would not occur. 
We shall refer to the game with $\mathrm{B}$ as a standard as the $\mathrm{b}$ game and to the game with $\mathrm{A}$ as $\mathrm{a}$ contingent standard as the $\mathrm{c}$ game. Suppose $\mathrm{A}$ is discovered first by firm 1 in the $\mathrm{c}$ game. Then firm 1 can either offer a license to firm 2 at fee $L$, in which case firm 2 can buy the license or not, or not offer a license. If firm 1 offers a license at fee $L$ and firm 2 buys, then furm 1 's expected return is

$$
F_{1 \mathrm{~A}}^{\mathrm{c}}=\left[\pi_{1}(\mathrm{~A} ; \mathrm{A}) / \mathrm{r}\right]+\mathrm{L}
$$

and firm 2 's expected return is

$$
S_{2 B}^{c}=\left[\pi_{2}(A ; A) / r\right]-L
$$

where $\pi_{\mathrm{i}}(\mathrm{A} ; \mathrm{A})$ is firm i's flow duopoly profits from selling $\mathrm{A}$ in both markets. If firm 1 does not license the patent, then country 2's government will not enforce B as the standard until its discovery because it is not credible to do so. Therefore, if firm 1 does not license, its expected return is

$$
\mathrm{F}_{1 \mathrm{~A}}^{\mathrm{n}}=\left[\pi_{1}(\mathrm{~A})+(\mu / \mathrm{r}) \pi_{1}^{\mathrm{b}}(\mathrm{A} ; \mathrm{B})\right] /(\mathrm{r}+\mu) \text {, and }
$$

firm 2's expected return is

$$
\mathrm{S}_{2 \mathrm{~B}}^{\mathrm{n}}=\left[(\mu / \mathrm{r}) \pi_{2}^{\mathrm{b}}(\mathrm{B} ; \mathrm{A})-\mathrm{k}_{2 \mathrm{~B}}\right] /(\mathrm{r}+\mu) .
$$

The assumption

$$
(r / \mu)<\left[\pi_{1}(\mathrm{~A}, \mathrm{~A})-\pi_{1}^{\mathrm{b}}(\mathrm{A} ; \mathrm{B})\right] /\left[\pi_{1}(\mathrm{~A})-\pi_{1}(\mathrm{~A} ; \mathrm{A})\right]
$$

is sufficient to guarantee that firm 1 will offer a license for any nonnegative fee (i.e., $F_{1 A}^{c}>F_{1 A}^{n}$ for any $L \geq 0$ ). Notice that in order for (A6) to hold, firm 1's profit from selling $A$ in both markets when it has licensed A must exceed its profit from its own market when A and B are both available. In this case (A6) holds for a high enough hazard rate because increasing the hazard rate speeds up the expected discovery date of $B$, and thus reduces the length of time firm 1 can earn monopoly profit from $\mathrm{A}$ in both markets. The assumption

$$
\pi_{2}(\mathrm{~A} ; \mathrm{A})>\pi_{2}^{\mathrm{i}}(\mathrm{B} ; \mathrm{A})+\pi_{2}^{2}(\mathrm{~B})=\pi_{2}^{\mathrm{b}}(\mathrm{B} ; \mathrm{A})
$$


is sufficient to guarantee that firm 2 will buy a license at a minimal positive fee (i.e., $S_{2 b}^{c}>S_{2 b}^{n}$ for a sufficiently small but positive fee L). This condition simply says flow profit if it buys the license exceeds flow profit under the standard when $A$ is available. ${ }^{12}$

Now suppose B is discovered first. Then firm 2 produces B for sale in both countries at least until $\mathrm{A}$ is discovered. The outcome of the licensing game now depends, in part, on whether firm 2 can sell both $A$ and $B$ in country 1 when it buys a license for $A$. Because this would reduce firm 1's flow profit from its own market (compared to duopoly production of $\mathrm{A}$ in both countries), it is reasonable to assume that firm 1 will not sell a license unless firm 2 agrees to stop selling B in country 1 . Hence, if firm 1 offers a license at fee $L$ and firm 2 buys, then firm 1 earns $\left[\pi_{1}(A ; A) / r\right]$ $+\mathrm{L}$ and firm 2 earns $\left[\pi_{2}(\mathrm{~A} ; \mathrm{A}) / \mathrm{\tau}\right]-\mathrm{L}$. Otherwise, $\mathrm{B}$ becomes the standard, so firm 1 earns $\pi_{1}^{b}(A ; B) / r$ and firm 2 earns $\pi_{2}^{b}(B ; A) / r$. Again, (A6) and (A7) are sufficient to ensure $A$ is licensed if it is discovered second by firm 1.

Theorem 4: Suppose country 2's government adopts the contingent standard policy and A is discovered by firm 1. Then, under (A1), (A2), (A3), (A6), and (A7); there exist values $L_{1}<0$ and $L_{2}>0$ such that the unique SPE of the licensing subgame induced by this policy is firm 1 offers the license at fee $L$ and firm 2 buys the license for any $L \in\left(L_{1}, L_{2}\right)$.

The proof of Theorem 4 shows that country 2's government can choose a small, but positive, license fee such that licensing occurs if $A$ is discovered by firm 1 . Thus, whether $A$ is discovered first or second, or by firm 1 or 2 , it becomes the standard in country 2 , ex post. As was the case with $A$ as an arbitrary standard, this means that $(a, a)$ is more likely to be the equilibrium in the $c$ game than with no policy. Even though this contingent standard makes doing

${ }^{12}$ (A6) and (A7) are stronger than is necessary for licensing to occur. All that is necessary is that $F_{1 A}^{c}>F_{1 A}^{n}, S_{2 b}^{c}>S_{2 b}^{n}$, and (5) still holds. A natural sufficient condition (which is also weaker than (A $\left.{ }^{1 A}\right)$ and $\left.(A 7)\right)^{2 b}$ is that the present value of both firms' profits under licensing exceeds the present value of both firms' expected profits without licensing,

$$
\left[\pi_{1}(\mathrm{~A} ; \mathrm{A})+\pi_{2}(\mathrm{~A} ; \mathrm{A})\right] / \mathrm{r}>\left\{\pi_{1}(\mathrm{~A})+(\mu / \mathrm{r})\left[\pi_{1}^{\mathrm{b}}(\mathrm{A} ; \mathrm{B})+\pi_{2}^{\mathrm{b}}(\mathrm{B} ; \mathrm{A})\right]\right\} /(\mathrm{r}+\mu) \text {. }
$$

We make the stronger assumptions because they guarantee the contingent standard is time consistent under natural rankings of consumer surplus. 
$\mathrm{R} \& \mathrm{D}$ on $\mathrm{B}$ less attractive, it is still possible that $(\mathrm{a}, \mathrm{b})$ will be the equilibrium. Notice, however, that now there is an incentive for firm 2 to drop out of the race and wait to acquire a license for A. Dropping out has the advantage of eliminating the uncertain flow costs of developing B, but also has the disadvantage of eliminating the possibility of earning monopoly profit with $B$.

Theorem 5: Under (A1), (A2), (A3), (A6), and (A7), if (5) holds and $k_{2 A}-k_{2 B}>$ $\mu\left(F_{2 A}^{c}-F_{2 B}^{c}\right)$, then the unique SPE for all $L \in\left(L_{l}, L_{2}\right)$ is:

(i) $\quad(a, b)$ if $k_{2 B}<\mu \pi_{2}(B) /(r+\mu)$.

(ii) $\quad(a, d)$ if $k_{2 B}>\mu \pi_{2}(B) /(r+\mu)$.

In the $c$ game, firm 1's advantage in developing A does not ensure that firm 2 will develop $B$ in equilibrium, as it did in the $b$ game and in the absence of policy. Firm 2 will deviate from this outcome, to wait to license the patent for $A$, if the flow cost of doing $R \& D$ to discover $B$ is greater than discounted expected monopoly profit with B. Several remarks about this are in order. First, it is possible that only A may be discovered under this policy even though both products would be discovered with no policy and with $\mathrm{B}$ as the standard. B never is discovered if $\mathrm{A}$ is discovered first.. This must occur if firm 2 delays in equilibrium, but it can also occur if firm 2 tries to develop B. Second, if firm 2 does delay, then it is obviously giving up the chance of discovering B first and earning monopoly profit until discovery of A. Hence this indicates that delaying is more likely to be an equilibrium the lower the expected return from discovering B first. That is, delaying is more likely the smaller the flow profit from B and/or the larger the flow cost of discovering $\mathrm{B}$. Delaying is also more likely the higher the return from acquiring the license, or the larger the duopoly profit from $\mathrm{A}$ and/or the smaller the license fee. Third, firm 1 is even willing to give a license to firm 2 (i.e., $L=0$ ) because this ensures firm 1 's product is adopted as a standard.

The remaining question of interest is whether the contingent policy is time consistent. The following theorem shows that if B as a standard increases flow welfare at the end of the game, the contingent standard policy is indeed time consistent.

Theorem 6 Assume the conditions of Theorem 5. The contingent standard policy is timeconsistent under (A4) if $B$ as a standard improves flow welfare after discovery of both products 
and if $C_{2}(A, A) \geq C_{2}(A)$, where $C_{2}(A, A)$ is country 2 's consumer surplus from duopoly production of $A$. The contingent policy is time-consistent under (A5) if $C_{2}(A, A)>C_{2}(A, B)$.

The intuition for this result is straightforward. If $B$ is discovered first, then in the period before $\mathrm{A}$ is discovered flow welfare is the same with both policies as with no policy. Once $\mathrm{A}$ is discovered, whether it is first or second, then the contingent standard results in licensing. After this occurs, flow welfare is higher with the contingent standard than with B as a standard (which by hypothesis is higher than with no policy). Firm 2 's flow profit must be higher because otherwise it would not buy a license. Consumers in country 2 are better off because consumer surplus from duopoly production of $\mathrm{A}$ exceeds that from monopoly production of $\mathrm{A}$, and therefore that from monopoly production of B when(A4) holds. Hence, the contingent standard is time consistent in the sense that it increases expected welfare, compared to that with no policy, at every date.

\section{Concluding Remarks}

As is always the case, our results are qualified by the assumptions from which they are derived. The strongest of these assumptions are that: the discovery dates of the products are exponentially distributed with constant hazard rates, and this is the only uncertainty in the model; the flow costs of R\&D are constant; and the foreign government is inactive. The effects of relaxing these assumptions on our results are, of course, open questions. Nevertheless, we believe our results are robust enough to survive many of these generalizations.

The key elements in our analysis are that: absent policy, the firms develop products that are different, but close substitutes; and the order of discovery of these products is uncertain. Under this scenario, an ex ante commitment to a single product as a standard will not, in general, be a time consistent policy because there is always the possibility that the other product will be discovered first and consumers will lose in the interim.

Allowing nonconstant hazard rates that reflect experience in $R \& D$ or variable $R \& D$ effort should not preclude simultaneous development of substitutes as a possible equilibrium outcome. If 
one firm has a large enough advantage (in greater initial experience or lower marginal cost of $R \& D$, for example), then the other firm would surely develop an inferior substitute instead of dropping out. This analysis would, of course, be more complicated, particularly because it is not clear that the parameter space could be partitioned in terms of equilibrium outcomes as conveniently as in Theorem 1. Nevertheless, for these parameters for which simultaneous development of substitutes is an equilibrium, our basic policy results should remain intact.

A more interesting extension would be to introduce another type of uncertainty. For example, a referee has suggested introducing the option of developing a third product, which is superior to the others (such as digital HDTV), in such a way as to examine the possibility of second mover advantages. This would be interesting, and naturally would expand the set of possible equilibrium outcomes. However, it seems clear that our results regarding the time consistency of policy would still obtain as long as some pair of different products are developed and the order of discovery is uncertain.

Finally, the assumption that the foreign government is inactive seems unduly restrictive. Indeed, allowing this government to choose standards policies could alter the equilibrium outcome of the R\&D game; but we cannot see how it would change our major policy results. Given the uncertain order of discovery, a policy employing standards will not, in general, be time consistent unless it is designed to depend at least upon the order of discovery (i.e., is state-contingent). In a game in which governments choose policies optimally, we would naturally expect results to depend on the order of government moves as well. While we might expect a Prisoner's Dilemma outcome, it is difficult to predict since such a game is much more complex than the one we consider and beyond the scope of this paper. 


\section{References}

Bagwell, K. and Staiger, R., "The Sensitivity of Strategic R\&D Policy to Market Conditions," Mimeo, Stanford University, 1989.

Beath, J., "Models of Technological Competition for the Analysis of Intellectual Property Rights and the Uruguay Round," Mimeo, 1990.

Besen, S.M. and Saloner, G., "The Economics of Telecommunications Standards," in R. Crandall and K. Flamm, eds., Changing the Rules: Technological Change, International Competition, and Regulation in Telecommunications, Washington: The Brookings Institution, 1989.

Choi, "Standardization and Experimentation: Ex Ante vs. Ex Post Standardization," Mimeo, CentER, 1993.

Choi, "Irreversible Choice of Certain Technologies with Network Externalities," Rand Journal of Economics 25, 1994, forthcoming.

Copeland, B., "Product Standards as Trade Policy in an International Duopoly," Mimeo, University of British Columbia, 1992.

Crane, R.J., The Politics of International Standards, Norwood, New Jersey: Ablex Publishing, 1979.

David, P., "Some New Standards for the Economics of Standardization in the Information Age," in P. Dasgupta and P. Stoneman, eds., Economic Policy and Technological Performance, Cambridge, England: Cambridge University.Press, 1987.

David, P. and Greenstein, S., "The Economics of Compatibility Standards: An Introduction to Recent Research," The Economics of Innovation and New Technology 1, 1990, 3-41.

Dixit, A., "A General Model of R\&D Competition and Policy," RAND Journal of Economics 19, 1988a, 317-326.

"International R\&D Competition and Policy," in A. M. Spence and H. A. Hazard (ed.), International Competitiveness, Cambridge: Ballinger, $1988 \mathrm{~b}$.

Farrell, J. and G. Saloner, "Standardization, Compatibility, and Innovation," RAND Journal of Economics 16, 1985, 70-83.

, Installed Base and Compatibility: Innovation, Product Preannouncements, and Predation," American Economic Review 76, 1986a, 940-955.

, "Standardization and Variety," Economic Letters 20, 1986b, 71-74. 1988, 235-251.

Farrell, J. and C. Shapiro, "Strategy and Standards in High-Definition Television," Brookings Papers: Microeconomics, 1992.

Fudenberg, D., R. Gilbert, J. Stiglitz, and J. Tirole, "Preemption, Leapfrogging, and Competition in Patent Races," European Economic Review 22, 1983, 3-31. 
GATT Secretariat, "Draft Final Act Embodying the Results of the Uruquay Round of Multilateral Trade Negotiations," Document MTN.TNC/W/FA, UR 91/0185, 1991.

Gilbert, R. and D. Newbery, "Preemptive Patenting and the Persistence of Monopoly," American Economic Review 72, 1982, 514-526.

Harris, C. and J. Vickers, "Perfect Equilibrium in a Model of a Race," Review of Economic Studies 52, 1985, 193-209.

Hazard, H. and H. Daems, "Tec hnical Standards and Competitive Advantage in World Trade," mimeo, Harvard University, 1988.

Katz, M. and C. Shapiro, "Network Extemalities, Competition, and Compatibility," American Economic Review 75, 1985, 424-440.

, "Technology Adoption in the Presence of Network Externalities," Journal of Political Economy 94, 1986a, 822-841.

, "Product Compatibility Choice in a Market with Technological Progress," Oxford Economic Papers: Special Issue on Industrial Organization, $1986 \mathrm{~b}$.

Kende, M., "Strategic Standardization in Trade with Network Externalities," mimeo, MIT, 1991.

Krishna, K., "High-Tech Trade Policy," in R. Baldwin, C. Hamilton, and A. Sapir (ed.), US-EC Trade Relations, Chicago: University of Chicago Press, 1988.

Lecraw, D. J., "Japanese Standards: A Barrier to Trade?" in H. Landis Gabel, ed., Product Standardization and Competitive Strategy, Elsevier Science Publishers, 1987.

Lippman, S. and K. McCardle, "Dropout Behavior in R\&D Races with Learning," RAND Journal of Economics 18, 1987, 287-295.

, "Preemption in R\&D Races," European Economic Review 32, 1988, 1661-1669.

Mayer, W., "The Tariff Equivalent of Import Standards," International Economic Review 23, $1982,723-734$.

Pelkmans, J. and R. Beuter, "Standardization and Competitiveness: Private and Public Strategies in the EC Color TV Industry," in H. Landis Gabel, ed., Product Standardization and Competitive Strategy, Elsevier Science Publishers, 1987.

Reinganum, J., "The Timing of Innovation: Research, Development, and Diffusion," in R. Schmalensee (ed.), The Handbook of Industrial Organization, Amsterdam: North Holland, 1989.

Shy, Oz, "International Standardization and Protection," The Sackler Institute of Economic Studies, 1991.

Shaked, A. and J. Sutton, "Relaxing Price Competition Through Product Differentiation," Review of Economic Studies 49, 1982, 3-13.

Sims, C., "HDTV: Will the U.S. Be in the Picture," New York Times, September 27, 1988, 27. 
Staiger, R. and Q. Tabellini, "Discretionary Trade Policy and Excessive Protection," American Economic Review 77, 1987, 823-837

U.S. Congress, Technology Task Policy Force, Report of the Committee on Science, Space, and Technology, Washington, D.C.: U.S. House of Representatives, 1988.

Office of Technology Assessment, Global Standards: Building Blocks for the

Future, TCT-512,Washington, DC.: U.S. Government Printing Office, March 1992.

Yanagawa, N., "Network Externalities and Trade Policies," mimeo, University of Tokyo, 1990. 


\section{Appendix 1}

Proof of Theorem 1. From Table 1:

$$
\begin{aligned}
& P_{1}(a, a)-P_{1}(b, a)=P_{1}(a, b)-P_{1}(b, b)=\left[\mu\left(F_{1 A}-F_{1 B}\right)-\left(k_{1 A}-k_{1 B}\right)\right] /(r+2 \mu) \text { and } \\
& P_{1}(a, d)-P_{1}(b, d)=\left[\mu\left(F_{1 A}-F_{1 B}\right)-\left(k_{1 A}-k_{1 B}\right)\right] /(r+\mu) .
\end{aligned}
$$

From the analogous payoffs for firm 2 ,

$$
\begin{aligned}
& P_{2}(a, a)-P_{2}(a, b)=P_{2}(b, a)-P_{2}(b, b)=\left[\mu\left(F_{2 A}-F_{2 B}\right)-\left(k_{2 A}-k_{2 B}\right)\right] /(r+2 \mu) \text { and } \\
& P_{2}(d, a)-P_{2}(d, b)=\left[\mu\left(F_{2 A}-F_{2 B}\right)-\left(k_{2 A}-k_{2 B}\right)\right] /(r+\mu) .
\end{aligned}
$$

Further note that $(A 1)-(A 3)$ imply $P_{1}(a, b)>P_{1}(d, b), P_{1}(a, d)>P_{1}(d, d)$,

$\mathrm{P}_{1}(\mathrm{~b}, \mathrm{a})>\mathrm{P}_{1}(\mathrm{~d}, \mathrm{a}), \mathrm{P}_{1}(\mathrm{~b}, \mathrm{~d})>\mathrm{P}_{1}(\mathrm{~d}, \mathrm{~d}), \mathrm{P}_{2}(\mathrm{~b}, \mathrm{a})>\mathrm{P}_{2}(\mathrm{~b}, \mathrm{~d}), \mathrm{P}_{2}(\mathrm{~d}, \mathrm{a})>\mathrm{P}_{2}(\mathrm{~d}, \mathrm{~d}), \mathrm{P}_{2}(\mathrm{a}, \mathrm{b})>\mathrm{P}_{2}(\mathrm{a}, \mathrm{d})$, and $\mathrm{P}_{2}(\mathrm{~d}, \mathrm{~b})>\mathrm{P}_{2}(\mathrm{~d}, \mathrm{~d})$.

Assume $\mu\left(F_{1 A}-F_{1 B}\right)>k_{1 A}-k_{1 B}$. Then $P_{1}\left(a, s_{2}\right)>P_{1}\left(b, s_{2}\right)$ for all $s_{2} \in\{a, b, d\}$. This plus $\mathrm{P}_{1}(\mathrm{~b}, \mathrm{a})>\mathrm{P}_{1}(\mathrm{~d}, \mathrm{a})$ implies $\mathrm{P}_{1}(\mathrm{a}, \mathrm{a})>\mathrm{P}_{1}(\mathrm{~d}, \mathrm{a})$, and so $\mathrm{P}_{1}\left(\mathrm{a}, \mathrm{s}_{2}\right)>\mathrm{P}_{1}\left(\mathrm{~d}, \mathrm{~s}_{2}\right)$ for all $\mathrm{s}_{2} \in\{\mathrm{a}, \mathrm{b}, \mathrm{d}\}$. Similarly, if $\mu\left(F_{1 A}-F_{1 B}\right)<k_{1 A}-k_{1 B}$, then $P_{1}\left(b, s_{2}\right)>P_{1}\left(a, s_{2}\right)$ for all $s_{2} \in\{a, b, d\}$. This plus $P_{1}(a, b)>P_{1}(d, b)$ implies $P_{1}(b, b)>P_{1}(d, b)$, and so $P_{1}\left(b, s_{2}\right)>P_{1}\left(d, s_{2}\right)$ for all $s_{2} \in\{a, b, d\}$. Analogously, we have $P_{2}\left(s_{1}, a\right)>P_{2}\left(s_{1}, b\right)$ and $P_{2}\left(s_{1}, a\right)>P_{2}\left(s_{1}, d\right)$ for all $s_{1} \in\{a, b, d\}$ if $\mu\left(F_{2 A}-F_{2 B}\right)>k_{2 A}-k_{2 B}$, but $P_{2}\left(s_{1}, b\right)>P_{2}\left(s_{1}, a\right)$ and $P_{2}\left(s_{1}, b\right)>P_{2}\left(s_{1}, d\right)$ for all $s_{2} \in\{a, b, d\}$ if $\mu\left(F_{2 A}-F_{2 B}\right)<k_{2 A}-k_{2 B}$. This proves the result when the firms are restricted to the stationary strategies $a, b$,

and $\mathrm{d}$.

Given the memorylessness property of the exponential distribution and the fact that hazard rates are constant, this is sufficient to prove the result in general. To see this, assume $\mu\left(F_{1 A}-F_{1 B}\right)$ $>k_{1 A}-k_{1 B}$ and $\mu\left(F_{2 A}-F_{2 B}\right)<k_{2 A}-k_{2 B}$, so $P_{1}\left(a, s_{2}\right)>P_{1}\left(b, s_{2}\right)$ and $P_{1}\left(a, s_{2}\right)>P_{1}\left(d, s_{2}\right)$ for all $s_{2} \in\{a, b, d\}$, and $P_{2}\left(s_{1}, b\right)>P_{2}\left(s_{1}, a\right)$ and $P_{2}\left(s_{1}, b\right)>P_{2}\left(s_{1}, d\right)$ for all $s_{1} \in\{a, b, d\}$. We first show that firm 1's payoff decreases if it deviates from a to any nonstationary strategy. We then show that firm 1's best reply remains a whenever firm 2 deviates "off the equilibrium path." 
Suppose firm 1 deviates from a by doing $R \& D$ on $B$ for a length of time $\Delta$ at any date $T$ before the first discovery date. The payoff from this is

$$
\begin{aligned}
& \int_{0}^{T} e^{-r t}\left(\mu F_{1 A}+\mu S_{1 A}-k_{1 A}\right) e^{-2 \mu t} d t+\int_{T}^{T+\Delta} e^{-\pi}\left(\mu F_{1 B}+\mu S_{1 A}-k_{1 B}\right) e^{-2 \mu t} d t \\
& +\int_{T}^{\infty} e^{-r t}\left(\mu F_{1 A}+\mu S_{1 A}-k_{1 A}\right) e^{-2 \mu t} d t \\
& =\left[1-e^{-(r+2 \mu) T}+e^{-(r+2 \mu)(T+\Delta)}\right]\left[\left(\mu F_{1 A}+\mu S_{1 A}-k_{1 A}\right) /(r+2 \mu)\right] \\
& +\left[e^{-(r+2 \mu) T}-e^{-(r+2 \mu)(T+\Delta)}\right]\left[\left(\mu F_{1 B}+\mu S_{1 A}-k_{1 A}\right) /(r+2 \mu)\right] \\
& =\left[1-e^{-(r+2 \mu) T}+e^{-(r+2 \mu)(T+\Delta)}\right] P_{1}(a, b)+\left[e^{-(r+2 \mu) T}-e^{-(r+2 \mu)(T+\Delta)}\right] P_{1}(b, b)<P_{1}(a, b)
\end{aligned}
$$

because $P_{1}(a, b)>P_{1}(b, b)$.

The same decrease in payoff occurs for any number of deviations. For example, suppose firm 1 alternates between $A$ and $B$ for intervals of length $\Delta$. That is, firm 1 does R\&D on $A$ from 0 to $\Delta$, on $\mathrm{B}$ from $\Delta$ to $2 \Delta$, on $\mathrm{A}$ from $2 \Delta$ to $3 \Delta$, on $\mathrm{B}$ from $3 \Delta$ to $4 \Delta$, and so on. The payoff from this strategy is

$$
\begin{aligned}
& \sum_{n=0}^{\infty}\left[\mathrm{e}^{-(\mathrm{r}+2 \mu)(2 \mathrm{n}) \Delta}-\mathrm{e}^{-(\mathrm{r}+2 \mu)(2 \mathrm{n}+1) \Delta}\right] \mathrm{P}_{1}(\mathrm{a}, \mathrm{b}) \\
& +\sum_{n=0}^{\infty}\left[\mathrm{e}^{-(\mathrm{r}+2 \mu)(2 \mathrm{n}+1) \Delta}-\mathrm{e}^{-(\mathrm{r}+2 \mu)(2 n+2) \Delta}\right] \mathrm{P}_{1}(\mathrm{~b}, \mathrm{~b})<\mathrm{P}_{1}(\mathrm{a}, \mathrm{b}) \text { because } \mathrm{P}_{1}(\mathrm{a}, \mathrm{b})>\mathrm{P}_{1}(\mathrm{~b}, \mathrm{~b}) .
\end{aligned}
$$

The same result obtains even if firm 1 alternates between $R \& D$ on $A$ and $R \& D$ on $B$ at every instant of time. Taking limits from above as $\Delta \rightarrow 0$ shows the payoff from this strategy is $(1 / 2) P_{1}(a, b)+(1 / 2) P_{1}(b, b)<P_{1}(a, b)$ as $P_{1}(a, b)>P_{1}(b, b)$. Similarly, a deviation to doing nothing from $T$ to $T+\Delta$ reduces firm 1's payoff because $P_{1}(a, b)>P_{1}(d, b)$. Hence, a is firm 1's best reply to $b$ in general.

Now we show that a is firm 1's best reply if firm 2 deviates from $b$. Suppose firm 2 deviates from $\mathrm{b}$ by doing $\mathrm{R} \& \mathrm{D}$ on $\mathrm{A}$ for a length of time $\Delta$ at any date $\mathrm{T}$ before the first discovery date. Then firm 1's payoff from $a$ is

$$
\begin{aligned}
& \int_{0}^{T} e^{-\pi t}\left(\mu F_{1 A}+\mu S_{1 A}-k_{1 A}\right) e^{-2 \mu t} d t+\int_{T}^{T+\Delta} e^{-r t}\left(\mu F_{1 A}+\mu S_{1 B}-k_{1 A}\right) e^{-2 \mu t} d t \\
& +\int_{T}^{\infty} e^{-\pi t}\left(\mu F_{1 A}+\mu S_{1 A}-k_{1 A}\right) e^{-2 \mu t} d t \\
& =\left[1-e^{-(r+2 \mu) T}+e^{-(r+2 \mu)(T+\Delta)}\right] P_{1}(a, b)+\left[e^{-(r+2 \mu) T}-e^{-(r+2 \mu)(T+\Delta)}\right] P_{1}(a, a)
\end{aligned}
$$

Similarly, firm 1's payoffs from $b$ and $d$ are

$$
=\left[1-e^{-(r+2 \mu) T}+e^{-(r+2 \mu)(T+\Delta)}\right] P_{1}(b, b)+\left[e^{-(r+2 \mu) T}-e^{-(r+2 \mu)(T+\Delta)}\right] P_{1}(b, a)
$$


and

$$
=\left[1-\mathrm{e}^{-(\mathrm{r}+2 \mu) \mathrm{T}}+\mathrm{e}^{-(\mathrm{r}+2 \mu)(\mathrm{T}+\Delta)}\right] \mathrm{P}_{1}(\mathrm{~d}, \mathrm{~b})+\left[\mathrm{e}^{-(\mathrm{r}+2 \mu) \mathrm{T}}-\mathrm{e}^{-(\mathrm{r}+2 \mu)(\mathrm{T}+\Delta)}\right] \mathrm{P}_{1}(\mathrm{~d}, \mathrm{a}),
$$

which are less than the payoff to a above because $P_{1}\left(a, s_{2}\right)>P_{1}\left(b, s_{2}\right)$ and $P_{1}\left(a, s_{2}\right)>P_{1}\left(d, s_{2}\right)$ for all $s_{2} \in\{a, b, d\}$.

Further, if firm 2 alternates between $B$ and $A$ for intervals of length $\Delta$ then firm 1's payoffs from $a, b$, and $d$ are, respectively,

$$
\begin{aligned}
& \sum_{n=0}^{\infty}\left[\mathrm{e}^{-(\mathrm{r}+2 \mu)(2 \mathrm{n}) \Delta}-\mathrm{e}^{-(\mathrm{r}+2 \mu)(2 \mathrm{n}+1) \Delta}\right] \mathrm{P}_{1}(\mathrm{a}, \mathrm{b}) \\
& +\sum_{n=0}^{\infty}\left[\mathrm{e}^{\left.-(\mathrm{r}+2 \mu)(2 \mathrm{n}+1) \Delta-\mathrm{e}^{-(\mathrm{r}+2 \mu)(2 \mathrm{n}+2) \Delta}\right] \mathrm{P}_{1}(\mathrm{a}, \mathrm{a})}\right. \\
& \sum_{\mathrm{n}=0}^{\infty}\left[\mathrm{e}^{-(\mathrm{r}+2 \mu)(2 \mathrm{n}) \Delta}-\mathrm{e}^{-(\mathrm{r}+2 \mu)(2 \mathrm{n}+1) \Delta}\right] \mathrm{P}_{1}(\mathrm{~b}, \mathrm{~b}) \\
& +\sum_{n=0}^{\infty}\left[\mathrm{e}^{\left.-(\mathrm{r}+2 \mu)(2 \mathrm{n}+1) \Delta-\mathrm{e}^{-(\mathrm{r}+2 \mu)(2 \mathrm{n}+2) \Delta}\right] \mathrm{P}_{1}(\mathrm{~b}, \mathrm{a})}\right.
\end{aligned}
$$

and

$$
\begin{aligned}
& \sum_{n=0}^{\infty}\left[\mathrm{e}^{-(\mathrm{r}+2 \mu)(2 \mathrm{n}) \Delta}-\mathrm{e}^{-(\mathrm{r}+2 \mu)(2 \mathrm{n}+1) \Delta}\right] \mathrm{P}_{1}(\mathrm{~d}, \mathrm{~b}) \\
& +\sum_{n=0}^{\infty}\left[\mathrm{e}^{-(\mathrm{r}+2 \mu)(2 \mathrm{n}+1) \Delta}-\mathrm{e}^{-(\mathrm{r}+2 \mu)(2 \mathrm{n}+2) \Delta}\right] \mathrm{P}_{1}(\mathrm{~d}, \mathrm{a})
\end{aligned}
$$

Again, the payoff to $a$ is greater than that to $b$ and that to $d$ because $P_{1}\left(a, s_{2}\right)>P_{1}\left(b, s_{2}\right)$ and $P_{1}\left(a, s_{2}\right)$ $>P_{1}\left(d, s_{2}\right)$ for all $s_{2} \in\{a, b, d\}$. And for the same reason, the same results obtain if firm 2 alternates between $\mathrm{B}$ and $\mathrm{A}$ at every instant of time. Taking limits from above as $\Delta \rightarrow 0$ shows the payoffs to firm 1 from $a, b$, and $d$ are $1 / 2 P_{1}(a, b)+1 / 2 P_{1}(a, a), 1 / 2 P_{1}(b, b)+1 / 2 P_{1}(b, a)$, and $1 / 2 P_{1}(d, b)+$ $1 / 2 P_{1}(d, a)$. An analogous argument shows that $a$ is firm 1 's best reply if firm 2 deviates to doing nothing for some time or deviates to some combination of $R \& D$ on A or nothing. Hence, a strongly dominates $\mathrm{b}$ and $\mathrm{d}$ for any deviation from $\mathrm{b}$ by firm 2 . Using the same technique as above, one can easily show that, for any deviation from b by firm 2 , a still gives firm 1 a greater payoff than any nonstationary strategy in which firm 1 does anything other than R\&D on A for any interval of time.

An argument analogous to the preceding shows that $\mu\left(F_{2 A}-F_{2 B}\right)<k_{2 A}-k_{2 B}$ implies $b$ is firm 2 's best reply to firm 1 's use of $a, b, d$, or any nonstationary strategy combining $R \& D$ on $A$, R\&D on $B$, or nothing. 
Finally, assume that $\mu\left(F_{2 A}-F_{2 B}\right)<k_{2 A}-k_{2 B}$ but $\mu\left(F_{1 A}-F_{1 B}\right)=k_{1 A}-k_{1 B}$. Then $P_{1}\left(a, s_{2}\right)=$ $P_{1}\left(b, s_{2}\right)$ for all $s_{2} \in\{a, b, d\}$, so there is a continuum of SPE. That is, from above, firm 1's payoff from $a$ is not only the same as that from $b$, but also the same as that from alternating between R\&D on A and R\&D on B. Analogously, there is a continuum of SPE in which firm 2 is "indifferent" between $R \& D$ on $A$ and $R \& D$ on $B$ if $\mu\left(F_{1 A}-F_{1 B}\right)>k_{1 A}-k_{1 B}$ but $\mu\left(F_{2 A}-F_{2 B}\right)=$ $k_{2 A}-k_{2 B}$. This completes the proof of. (ii). The proofs of (i), (iii), and (iv) are entirely analogous.

Proof of Theorem 2. In the absence of a standard, both firms racing for $\mathrm{A},(\mathrm{a}, \mathrm{a})$, is the unique SPE for all parameters in the set $D=\left\{-M \leq k_{1 A}-k_{1 B}<\mu\left(F_{1 A}-F_{1 B}\right)\right.$ and $-M \leq k_{2 A}-k_{2 B}<$ $\left.\mu\left(F_{2 \mathrm{~A}}-\mathrm{F}_{2 \mathrm{~B}}\right)\right\}$, and both firms racing for $\mathrm{B},(\mathrm{b}, \mathrm{b})$ is the unique SPE for all parameters in the set $\mathrm{E}$ $=\left\{M \geq k_{1 A}-k_{1 B}>\mu\left(F_{1 A}-F_{1 B}\right)\right.$ and $\left.M \geq k_{2 A}-k_{2 B}>\mu\left(F_{2 A}-F_{2 B}\right)\right\}$.

If $A$ is imposed as a standard in country $m,(a, a)$ is the unique SPE for all parameter values in the set $\mathrm{F}=\left\{-\mathrm{M} \leq \mathrm{k}_{1 \mathrm{~A}}-\mathrm{k}_{1 \mathrm{~B}}<\mu\left(\mathrm{F}_{1 \mathrm{~A}}^{\mathrm{a}}-\mathrm{F}_{1 \mathrm{~B}}^{\mathrm{a}}\right)\right.$ and $\left.-\mathrm{M} \leq \mathrm{k}_{2 \mathrm{~A}}-\mathrm{k}_{2 \mathrm{~B}}<\mu\left(\mathrm{F}_{2 \mathrm{~A}}^{\mathrm{a}}-\mathrm{F}_{2 \mathrm{~B}}^{\mathrm{a}}\right)\right\}$. Because $F_{i A}^{a}-F_{i B}^{a}>F_{i A}-F_{i B}$ for $i=1,2$, the area of $F$ is larger than the area of $D$. Hence, if all parameter values in $S$ are equally likely, imposition of the standard increases the probability that $(\mathrm{a}, \mathrm{a})$ is the unique SPE because $\left[\mathrm{M}+\mu\left(\mathrm{F}_{1 \mathrm{~A}}^{\mathrm{a}}-\mathrm{F}_{1 \mathrm{~B}}^{\mathrm{a}}\right)\right]\left[\mathrm{M}+\mu\left(\mathrm{F}_{2 \mathrm{~A}}^{\mathrm{a}}-\mathrm{F}_{2 \mathrm{~B}}^{\mathrm{a}}\right)\right] / 4 M^{2}>$ $\left[\mathrm{M}+\mu\left(\mathrm{F}_{1 \mathrm{~A}}-\mathrm{F}_{1 \mathrm{~B}}\right)\right]\left[\mathrm{M}+\mu\left(\mathrm{F}_{2 \mathrm{~A}}-\mathrm{F}_{2 \mathrm{~B}}\right)\right] / 4 M^{2}$.

The proof for imposing $B$ as a standard is analogous since $F_{i A}^{b}-F_{i B}^{b}<F_{i A}-F_{i B}$ for $i=1,2$ and $(b, b)$ is the unique equilibrium for all parameters in the set $G=\left\{M \geq k_{1 A}-k_{1 B}>\mu\left(F_{1 A}^{b}-F_{1 B}^{b}\right)\right.$ and $\left.M \geq k_{2 A}-k_{2 B}>\mu\left(F_{2 A}^{b}-F_{2 B}^{b}\right)\right\}$ when $B$ is the standard.

Proof of Theorem 3. If $\mathrm{W}_{1}\left(\mathrm{~F}_{1 \mathrm{~A}}^{\mathrm{b}}\right), \mathrm{W}_{1}\left(\mathrm{~S}_{1 \mathrm{~A}}^{\mathrm{b}}\right), \mathrm{W}_{2}\left(\mathrm{~F}_{2 \mathrm{~B}}^{\mathrm{b}}\right)$, and $\mathrm{W}_{2}\left(\mathrm{~S}_{2 \mathrm{~B}}^{\mathrm{b}}\right)$ are the expressions for expected welfare at the first discovery date under the standard, then these are defined by (6)-(9) with $\pi_{i}^{b}(\cdot)$ and $C_{i}^{b}(\cdot)$ replacing $\pi_{i}(\bullet)$ and $C_{i}(\bullet)$. Similarly, let $W_{1}^{b}(a, b)$ and $W_{2}^{b}(a, b)$ be initial expected welfare under the standard. Then these are defined by $(10)$ and (11) with $\mathrm{W}_{1}\left(\mathrm{~F}_{1 \mathrm{~A}}^{\mathrm{b}}\right)$, $\mathrm{W}_{1}\left(\mathrm{~S}_{1 \mathrm{~A}}^{\mathrm{b}}\right), \mathrm{W}_{2}\left(\mathrm{~F}_{2 \mathrm{~B}}^{\mathrm{b}}\right)$, and $\mathrm{W}_{2}\left(\mathrm{~S}_{2 \mathrm{~B}}^{\mathrm{b}}\right)$ replacing $\mathrm{W}_{1}\left(\mathrm{~F}_{1 \mathrm{~A}}\right), \mathrm{W}_{1}\left(\mathrm{~S}_{1 \mathrm{~A}}\right), \mathrm{W}_{2}\left(\mathrm{~F}_{2 \mathrm{~B}}\right)$, and $\mathrm{W}_{2}\left(\mathrm{~S}_{2 \mathrm{~B}}\right)$. One can show that $\mathrm{W}_{2}\left(\mathrm{~F}_{2 \mathrm{~B}}\right)-\mathrm{W}_{2}\left(\mathrm{~F}_{2 \mathrm{~B}}^{\mathrm{b}}\right)=(\mu / \mathrm{r})\left[\pi_{2}(\mathrm{~B} ; \mathrm{A})-\pi_{2}^{\mathrm{b}}(\mathrm{B} ; \mathrm{A})+\mathrm{C}_{2}(\mathrm{~A}, \mathrm{~B})-\right.$ 
$\left.C_{2}^{b}(A, B)\right] /(r+\mu)$ and $W_{2}\left(S_{2 B}\right)-W_{2}\left(S_{2 B}^{b}\right)=\left\{C_{2}(A)+(\mu / r)\left[\pi_{2}(B ; A)-\pi_{2}^{b}(B ; A)+C_{2}(A, B)-\right.\right.$ $\left.\left.C_{2}^{b}(A, B)\right]\right\} /(r+\mu)$. After both $A$ and $B$ are discovered, country 2's flow welfare is $\pi_{2}^{b}(B ; A)+$ $C_{2}^{b}(A, B)$ with the standard and $\pi_{2}(B ; A)+C_{2}(A, B)$ without it, so it reduces flow welfare if and only if $\pi_{2}(B ; A)-\pi_{2}^{b}(B ; A)+C_{2}(A, B)-C_{2}^{b}(A, B)>0$. Hence, $W_{2}\left(F_{2 B}\right)>W_{2}\left(F_{2 B}^{b}\right)$ and $\mathrm{W}_{2}\left(\mathrm{~S}_{2 \mathrm{~B}}\right)>\mathrm{W}_{2}\left(\mathrm{~S}_{2 \mathrm{~B}}^{\mathrm{b}}\right)$, whence $\mathrm{W}_{2}(\mathrm{a}, \mathrm{b})>\mathrm{W}_{2}^{\mathrm{b}}(\mathrm{a}, \mathrm{b})$.

If flow welfare is higher with the standard after both are discovered, $\pi_{2}(B ; A)-\pi_{2}^{b}(B ; A)+$ $\mathrm{C}_{2}(\mathrm{~A}, \mathrm{~B})-\mathrm{C}_{2}^{\mathrm{b}}(\mathrm{A}, \mathrm{B})=\pi_{2}^{2}(\mathrm{~B} ; \mathrm{A})-\pi_{2}^{2}(\mathrm{~B})+\mathrm{C}_{2}(\mathrm{~A}, \mathrm{~B})-\mathrm{C}_{2}(\mathrm{~B})<0$, then $\mathrm{W}_{2}\left(\mathrm{~F}_{2 \mathrm{~B}}^{\mathrm{b}}\right)>\mathrm{W}_{2}\left(\mathrm{~F}_{2 \mathrm{~B}}\right)$. Also $\mathrm{W}_{2}\left(\mathrm{~S}_{2 \mathrm{~B}}^{\mathrm{b}}\right)>\mathrm{W}_{2}\left(\mathrm{~S}_{2 \mathrm{~B}}\right)$ if $\left\{\mathrm{C}_{2}(\mathrm{~A})+(\mu / \mathrm{r})\left[\pi_{2}(\mathrm{~B} ; \mathrm{A})-\pi_{2}^{\mathrm{b}}(\mathrm{B}, \mathrm{A})-\mathrm{C}_{2}(\mathrm{~B})+\mathrm{C}_{2}(\mathrm{~A}, \mathrm{~B})\right]\right\} /(\mathrm{r}+\mu)<0$.

Hence, $C_{2}(A)<(\mu / r)\left[\pi_{2}^{2}(B)-\pi_{2}^{2}(B ; A)+C_{2}(B)-C_{2}(A ; B)\right]$ implies $W_{2}^{b}(a, b)>$ $\mathrm{W}_{2}(\mathrm{a}, \mathrm{b})$. However, note that $\mathrm{C}_{2}(A)>0$ implies $\mathrm{W}_{2}\left(\mathrm{~S}_{2 \mathrm{~B}}\right)>\mathrm{W}_{2}\left(\mathrm{~S}_{2 \mathrm{~B}}^{\mathrm{b}}\right)$ can hold. Further, because $\mathrm{W}_{2}(\mathrm{a}, \mathrm{b})-\mathrm{W}_{2}^{\mathrm{b}}(\mathrm{a}, \mathrm{b})=\mu\left[\mathrm{W}_{2}\left(\mathrm{~F}_{2 \mathrm{~B}}\right)-\mathrm{W}_{2}\left(\mathrm{~F}_{2 \mathrm{~B}}^{\mathrm{b}}\right)+\mathrm{W}_{2}\left(\mathrm{~S}_{2 \mathrm{~B}}\right)-\mathrm{W}_{2}\left(\mathrm{~S}_{2 \mathrm{~B}}^{\mathrm{b}}\right)\right] /(\mathrm{r}+2 \mu)$, it is possible that $\mathrm{W}_{2}\left(\mathrm{~F}_{2 \mathrm{~B}}^{\mathrm{b}}\right)>\mathrm{W}_{2}\left(\mathrm{~F}_{2 \mathrm{~B}}\right), \mathrm{W}_{2}\left(\mathrm{~S}_{2 \mathrm{~B}}\right)>\mathrm{W}_{2}\left(\mathrm{~S}_{2 \mathrm{~B}}^{\mathrm{b}}\right)$, and either $\mathrm{W}_{2}^{\mathrm{b}}(\mathrm{a}, \mathrm{b})>\mathrm{W}_{2}(\mathrm{a}, \mathrm{b})$ or $\mathrm{W}_{2}(\mathrm{a}, \mathrm{b})>\mathrm{W}_{2}^{\mathrm{b}}(\mathrm{a}, \mathrm{b})$.

Proof of Theorem 4. Firm 2's strongly dominant strategy is to buy a license if $S_{2 B}^{c}>S_{2 B}^{n}$ (when $A$ is discovered first) and $\left[\pi_{2}(A ; A) / r\right]-L>\pi_{2}^{b}(B ; A) / r$ (when $B$ is discovered first). It is easily shown that $\left[\pi_{2}(\mathrm{~A} ; \mathrm{A}) / \mathrm{r}\right]-\mathrm{L}>\pi_{2}^{\mathrm{b}}(\mathrm{B} ; \mathrm{A}) / \mathrm{r}$ implies $\mathrm{S}_{2 \mathrm{~B}}^{\mathrm{c}}>\mathrm{S}_{2 \mathrm{~B}}^{\mathrm{n}}$. Hence, whether $\mathrm{A}$ is discovered first or second, firm 2's strongly dominant strategy is to buy if $\left[\pi_{2}(A ; A) / r\right]-L>\pi_{2}^{b}(B ; A) / r$, or

$$
\mathrm{L}<\mathrm{L}_{2}=\left[\pi_{2}(\mathrm{~A} ; \mathrm{A})-\pi_{2}^{\mathrm{b}}(\mathrm{B} ; \mathrm{A})\right] / \mathrm{r},
$$

where (A1) and (A7) imply $L_{2}>0$. Therefore, given any compulsory fee $L<L_{2}$, firm 1's strongly dominant strategy is to offer to sell a license at $L$ if $F_{1 A}^{c}>F_{1 A}^{n}$ (when $A$ is discovered first) and $\left[\pi_{1}(\mathrm{~A} ; \mathrm{A}) / \mathrm{r}\right]+\mathrm{L}>\pi_{1}^{\mathrm{b}}(\mathrm{A} ; \mathrm{B}) / \mathrm{r}$ (when $\mathrm{B}$ is discovered first). Because $\mathrm{F}_{1 \mathrm{~A}}^{\mathrm{c}}>\mathrm{F}_{1 \mathrm{~A}}^{\mathrm{n}}$ implies $\left[\pi_{1}(\mathrm{~A} ; \mathrm{A}) / \mathrm{r}\right]+\mathrm{L}>\pi_{1}^{\mathrm{b}}(\mathrm{A} ; \mathrm{B}) / \mathrm{r}$, whether $\mathrm{A}$ is discovered first or second, firm l's strongly dominant strategy is to offer to sell for any $L<L_{2}$ if $F_{1 A}^{c}>F_{1 A}^{n}$. One can show that $F_{1 A}^{c}>F_{1 A}^{n}$ if and only if

$$
\mathrm{L}>\mathrm{L}_{1}=\left[\left\{\pi_{1}(\mathrm{~A})+(\mu / \mathrm{r}) \pi_{1}^{\mathrm{b}}(\mathrm{A} ; \mathrm{B})\right\} /(\mathrm{r}+\mu)\right]-\left[\pi_{1}(\mathrm{~A} ; \mathrm{A}) / \mathrm{r}\right],
$$

where (A1) and (A6) imply $L_{1}<0$. Thus, whether $A$ is discovered first or second, the unique SPE of this licensing game is firm 1 offers to sell and firm 2 buys for all $L \in\left(L_{1}, L_{2}\right)$. 
Proof of Theorem 5. Under the contingent policy,

$$
\begin{aligned}
& P_{1}^{c}(a, a)-P_{1}^{c}(b, a)=P_{1}^{c}(a, b)-P_{1}^{c}(b, b)=\left[F_{1 A}^{c}-F_{1 B}^{c}-\left(k_{1 A}-k_{1 B}\right)\right] /(r+2 \mu), \\
& P_{1}^{c}(a, d)-P_{1}^{c}(b, d)=\left[F_{1 A}^{c}-F_{1 B}^{c}-\left(k_{1 A}-k_{1 B}\right)\right] /(r+\mu), \\
& P_{2}^{c}(a, a)-P_{2}^{c}(a, b)=P_{2}^{c}(b, a)-P_{2}^{c}(b, b)=\left[F_{2 A}^{c}-F_{2 B}^{c}-\left(k_{2 A}-k_{2 B}\right)\right] /(r+2 \mu), \text { and } \\
& P_{2}^{c}(d, a)-P_{2}^{c}(d, b)=\left[F_{2 A}^{c}-F_{2 B}^{c}-\left(k_{2 A}-k_{2 B}\right)\right] /(r+\mu) .
\end{aligned}
$$

Because $F_{1 A}^{c}>F_{1 A}^{b}$ and $F_{1 B}^{c}<F_{1}^{b}$, it follows that $k_{1 A}-k_{1 B}<\mu\left(F_{1 A}^{b}-F_{1 B}^{b}\right)$ implies $k_{1 A}-k_{1 B}<\mu\left(F_{1 A}^{c}-F_{1 B}^{c}\right)$. Moreover, (A1), (A2), and (A3) imply $P_{1}^{c}(a, b)>P_{1}^{c}(d, b)$, $P_{1}^{c}(a, d)>P_{1}^{c}(d, d)$, and $P_{1}^{c}(b, a)>P_{1}^{c}(d, a)$. Hence, if (5) holds, then developing $A$ is firm $1^{\prime} s$ strongly dominant strategy because $P_{1}^{c}\left(a, s_{2}\right)>P_{1}^{c}\left(b, s_{2}\right)$ and $P_{1}^{c}\left(a, s_{2}\right)>P_{1}^{c}\left(d, s_{2}\right)$ for $s_{2} \in\{a, b, d\}$. Because $k_{2 A}-k_{2 B}>\mu\left(F_{2 A}^{c}-F_{2 B}^{c}\right)$ implies $P_{2}^{c}(a, b)>P_{2}^{c}(a, a)$, the SPE must have firm 1 developing $A$ and firm 2 either developing $B$, delaying, or randomizing on these two pure strategies. The result follows from the fact that $\mathrm{P}_{2}^{c}(a, b) \underset{<}{\geq} \mathrm{P}_{2}^{c}(a, d)$ if and only if $\mu \pi_{2}(B) /(r+\mu) \underset{<}{\gtrless} k_{2 B}$. Moreover, if $\pi(B) \leq(r+\mu) \pi_{2}^{1}(B ; A) / \mu$, then $k_{2 B} \geq \mu \pi_{2}(B) /(r+\mu)$ and (A2) can hold simultaneously, so (ii) can occur.

Proof of Theorem 6 Under these assumptions, $(a, b)$ is the unique SPE in the bame and the game with no policy, while in the $c$ game the unique $S P E$ is $(a, b)$ if $k_{2 B}<\mu \pi_{2}(B) /(r+\mu)$ and (a,d) if $k_{2 B}>\mu \pi_{2}(B) /(r+\mu)$. First suppose $k_{2 B}<\mu \pi_{2}(B) /(r+\mu)$. Then $W_{2}^{c}(a, b)-W_{2}(a, b)=$ $\mu\left[W_{2}\left(F_{2 B}^{c}\right)-W_{2}\left(F_{2 B}\right)+W_{2}\left(S_{2 B}^{c}\right)-W_{2}\left(S_{2 B}\right)\right] /(r+2 \mu)$. One can show $W_{2}\left(F_{2 B}^{c}\right)>W_{2}\left(F_{2 B}\right)$ if and only if $\mathrm{L}<\mathrm{L}^{\mathrm{w}}$, where

$$
L^{w}=\left[\pi_{2}(A ; A)-\pi_{2}(B ; A)+C_{2}(A, A)-C_{2}(A, B)\right] / r .
$$

Similarly, $W_{2}\left(S_{2 B}^{c}\right)>W_{2}\left(S_{2 B}\right)$ if and only if $L<L^{w b}$, where

$L^{\text {wb }}=\left[\pi_{2}(A ; A) / r\right]-\left[\left\{(\mu / r) \pi_{2}(B ; A)-k_{2 B}\right\} /(r+\mu)\right]+$

$\left[C_{2}(A, A) / r\right]-\left[\left\{C_{2}(A)+(\mu / r) C_{2}(A, B)\right\} /(r+\mu)\right]$. 
One can show that $(\mathrm{A} 4), \pi_{2}^{\mathrm{b}}(\mathrm{B} ; \mathrm{A})+\mathrm{C}_{2}^{\mathrm{b}}(\mathrm{A}, \mathrm{B})>\pi_{2}(\mathrm{~B} ; \mathrm{A})+\mathrm{C}_{2}(\mathrm{~A}, \mathrm{~B})$, and $\mathrm{C}_{2}(\mathrm{~A}, \mathrm{~A}) \geq \mathrm{C}_{2}(\mathrm{~A})$ imply both $\mathrm{L}^{\mathrm{w}}>\mathrm{L}_{2}$ and $\mathrm{L}^{\mathrm{wb}}>\mathrm{L}_{2}$, so $\mathrm{W}_{2}\left(\mathrm{~F}_{2 \mathrm{~B}}^{\mathrm{c}}\right)>\mathrm{W}_{2}\left(\mathrm{~F}_{2 \mathrm{~B}}\right), \mathrm{W}_{2}\left(\mathrm{~S}_{2 \mathrm{~B}}^{\mathrm{c}}\right)>\mathrm{W}_{2}\left(\mathrm{~S}_{2 \mathrm{~B}}\right)$, and thus $\mathrm{W}_{2}^{c}(\mathrm{a}, \mathrm{b})>\mathrm{W}_{2}(\mathrm{a}, \mathrm{b})$.

Now suppose $k_{2 B}>\mu \pi_{2}(B) /(r+\mu)$ so $W_{2}^{c}(a, d)=\mu W_{2}\left(S_{2 B}^{c}\right) /(r+\mu)$. One can show $\mathrm{W}_{2}^{c}(\mathrm{a}, \mathrm{d})>\mathrm{W}_{2}(\mathrm{a}, \mathrm{b})$ if and only if $\mathrm{L}<\mathrm{L}^{\mathrm{wd}}$, where $L^{\text {wd }}=\left[\left\{\pi_{2}(A ; A)+C_{2}(A, A)\right\} / r\right]-\left[\left\{\pi_{2}(B)+C_{2}(B)+2(\mu / r)\left[\pi_{2}(A ; B)+C_{2}(A, B)\right]\right\} /(r+2 \mu)\right]+$ $\left[k_{2 B} / \mu\right]$. Under $(A 4), \pi_{2}^{P}(B ; A)+C_{2}^{P}(A, B)>\pi_{2}(B ; A)+C_{2}(A, B), C_{2}(A, A) \geq C_{2}(A)$, and $k_{2 B}>$ $\mu \pi_{2}(B) /(r+\mu)$ imply $L^{w d}>L_{2}$, we have $W_{2}^{c}(a, d)>W_{2}(a, b)$ also.

Under (A5) one can show $L^{w}>L_{2}, L^{\text {wb }}>L_{2}$, and $L^{\text {wd }}>L_{2}$ as long as $C_{2}(A, A)>$ $C_{2}(A, B)$. This is reasonable since $A$ is considered superior to $B$. 


\section{Appendix 2}

\section{An example using the Shaked and Sutton quality differentiation structure}

This section presents a concrete example to underscore the importance of the time inconsistency problem and to demonstrate the superiority of a state contingent policy over a simple standard. Consider a Shaked and Sutton vertical (quality) differentiation model where a consumer has the following preferences:

$$
U= \begin{cases}\theta s_{k}-p_{k} & \text { if he buys product } k \text { with quality } s_{k} ; k=\mathrm{A}, \mathrm{B} . \\ 0 & \text { if he buys nothing. }\end{cases}
$$

$\theta$, a positive real number, is a taste parameter uniformly distributed over the interval $[\underline{\theta}, \bar{\theta}]$, where $\underline{\theta} \geq 0$ and $\bar{\theta}=\underline{\theta}+1$. Product $\mathrm{A}$ is superior to B, i.e., $s_{A}>s_{B}>0$. For simplicity, let consumer tastes be identical across the two countries. Assume the firms simultaneously choose quantities after developing their respective products and unit production costs are normalized to zero.

First, in the absence of any policy, suppose firm i, $\mathrm{i}=1,2$; develops product $k, k=\mathrm{A}, \mathrm{B}$; and the other product has not yet been discovered by the rival. Then, a consumer in country $\mathrm{m}, \mathrm{m}$ $=1,2$; buys the product only if $\theta s_{k}-p_{k m} \geq 0$, i.e., demand for product $k$ in country $\mathrm{m}$ is given by

$$
D_{k m}\left(p_{k m}\right)=h_{m}\left\{\bar{\theta}-\left(p_{k m} / s_{k}\right)\right\} ; k=\mathrm{A}, \mathrm{B} ; m=1,2 \text {. }
$$

where $h_{m}$ is the number of consumers in country $\mathrm{m}$.

Simple optimization yields i's maximum monopoly profit in country $\mathrm{m}$ as

$$
\Pi_{i}^{m}(k)=\left(h_{m} \bar{\theta}^{2} s_{k}\right) / 4
$$

Hence, if firm 1 develops $A$ and firm 2 develops B, then aggregate profits are

$$
\Pi_{1}(A)=\left(h_{1}+h_{2}\right)\left(\bar{\theta}^{2} s_{A}\right) / 4 \quad \text { and } \quad \Pi_{2}(B)=\left(h_{1}+h_{2}\right)\left(\bar{\theta}^{2} s_{B}\right) / 4
$$

Consumer surplus in country $\mathrm{m}$ when only product $\mathrm{k}$ is available is easily calculated as ${ }^{1}$

$$
C_{m}(k)=\left(h_{m} \bar{\theta}^{2} s_{k}\right) / 8
$$

${ }^{1}$ Consumer surplus is computed using the formula $C_{m}(k)=h_{m}\left\{\int_{\bar{\theta}}^{\bar{\theta}}\left(\theta s_{k}-p_{k}\right) d \theta\right\}$, where $\tilde{\theta}=$
$p_{k} / s_{k}$ 
Now suppose both products have been discovered, i.e., firm 1 has developed A and firm 2 has discovered $\mathrm{B}$. The consumer in country $\mathrm{m}$ who is indifferent between buying $\mathrm{A}$ and buying $\mathrm{B}$ is characterized by the taste parameter $\theta_{1}$ where $\theta_{1}=\left(p_{A m}-p_{B m}\right) /\left(s_{A}-s_{B}\right)$. The consumer who is indifferent between buying $\mathrm{B}$ and between buying nothing has a taste parameter $\theta_{0}$ where $\theta_{0}=p_{B m} / s_{B}$. Product $\mathrm{A}$ is bought by all consumers with $\theta \in\left[\theta_{1}, \bar{\theta}\right]$ and $\mathrm{B}$ is purchased by consumers with $\theta \in\left[\theta_{0}, \theta_{1}\right]$ while all those consumers who have $\theta \in\left[\underline{\theta}, \theta_{0}\right]$ will buy neither good. Hence, the demand functions for $\mathrm{A}$ and $\mathrm{B}$ are respectively given by

$$
D_{A m}\left(p_{A m}, p_{B m}\right)=h_{m}\left(\bar{\theta}-\theta_{1}\right) \quad \text { and } \quad D_{B m}\left(p_{A m}, p_{B m}\right)=h_{m}\left(\theta_{1}-\theta_{0}\right)
$$

Note that the market is assumed to be not covered since without this assumption the demand functions cannot be inverted and the Cournot equilibrium is not well defined.

Define $\bar{\alpha}=\left(2 s_{A}-s_{B}\right) /\left(4 s_{A}-s_{B}\right)$ and $\underline{\alpha}=s_{A} /\left(4 s_{A}-s_{B}\right)$. Then, the Nash equilibrium aggregate profits when firm 1 sells $A$ and firm 2 sells $B$, in the absence of any standard, are given by

$$
\Pi_{1}(A ; B)=\left(h_{1}+h_{2}\right) \bar{\alpha}^{2} \bar{\theta}^{2} s_{A} \quad \text { and } \quad \Pi_{2}(B ; A)=\left(h_{1}+h_{2}\right) \underline{\alpha}^{2} \bar{\theta}^{2} s_{B}
$$

Consumer surplus in country $m$ when both $A$ and $B$ are available is given by ${ }^{2}$

$$
C_{m}(A, B)=\frac{h_{m} \bar{\theta}^{2} s_{A}}{2\left(4 s_{A}-s_{B}\right)^{2}}\left\{4 s_{A}^{2}-s_{B}^{2}+s_{A} s_{B}\right\}
$$

From the above relations, it may be verified that assumptions (A1) and (A4) are always satisfied for any $s_{A}>s_{B}$.

Now, consider the policy game (b game) where country 2's government sets product B as the standard in its own country. Aggregate profits in the b game can be derived in straightforward fashion and we get

$$
\begin{array}{lll}
\Pi_{1}^{b}(A)=\left(h_{1} \bar{\theta}^{2} s_{A}\right) / 4 & \text { and } & \Pi_{1}^{b}(A ; B)=h_{1} \bar{\alpha}^{2} \bar{\theta}^{2} s_{A} \\
\Pi_{2}^{b}(B)=\left(h_{1}+h_{2}\right)\left(\bar{\theta}^{2} s_{B}\right) / 4 & \text { and } & \Pi_{2}^{b}(B ; A)=\left\{h_{1} \underline{\alpha}^{2}+\frac{h_{2}}{4}\right\} \bar{\theta}^{2} s_{B}
\end{array}
$$

The relevant expressions with respect to consumer surplus are given by

${ }^{2}$ Consumer surplus is calculated using the formula

$$
C_{m}(A, B)=h_{m}\left\{\int_{\theta_{1}}^{\bar{\theta}}\left(\theta s_{A}-p_{A}\right) d \theta+\int_{\theta_{0}}^{\theta_{1}}\left(\theta s_{B}-p_{B}\right) d \theta\right\}
$$




$$
\begin{aligned}
& C_{1}^{b}(A)=C_{1}(A) ; C_{1}^{b}(B)=C_{1}(B) \quad \text { and } \quad C_{1}^{b}(A, B)=C_{1}(A, B) \\
& C_{2}^{b}(A)=0 ; \quad C_{2}^{b}(B)=C_{2}(B) \quad \text { and } \quad C_{2}^{b}(A, B)=C_{2}(B)
\end{aligned}
$$

These profit and consumer surplus expressions can now be used to compute welfare at different dates and the following relations can be derived after some algebraic manipulations.

Lemma: Define $\lambda=\left[\frac{4 s_{A}{ }^{2}-s_{B}{ }^{2}+s_{A} s_{B}}{\left(4 s_{A}-s_{B}\right)^{2}}\right]$ and recall that $\underline{\alpha}=s_{A} /\left(4 s_{A}-s_{B}\right)$. Then,
(i) $\quad W_{2}\left(F_{2 B}^{b}\right) \gtreqless W_{2}\left(F_{2 B}\right)$
if and only if
$\left(3-8 \underline{\alpha}^{2}\right) s_{B} \gtreqless 4 s_{A} \lambda$.
(ii) $\quad W_{2}^{b}(a, b) \gtreqless W_{2}(a, b)$
if and only if
$\left(3-8 \underline{\alpha}^{2}\right) s_{B} \gtreqless 4 s_{A} \lambda+\frac{s_{A}}{2\left(\frac{\mu}{r}\right)}$.
(iii) $W_{2}\left(S_{2 B}^{b}\right) \gtreqless W_{2}\left(S_{2 B}\right)$
if and only if
$\left(3-8 \underline{\alpha}^{2}\right) s_{B} \gtreqless 4 s_{A} \lambda+\frac{s_{A}^{r}}{\left(\frac{\mu}{r}\right)}$.

In this example, the gain to firm 2 from $B$ as a standard exceeds the loss to consumers if and only if $\left(3-8 \underline{\alpha}^{2}\right) s_{B}>4 s_{A} \lambda$. However, the simple standard increases welfare at all dates only if $\left(3-8 \underline{\alpha}^{2}\right) s_{B}>4 s_{A} \lambda+\frac{s_{A}}{\left(\frac{\mu}{r}\right)}$. Otherwise, the policy may be time inconsistent as characterized in Theorem 3. For instance, with $s_{A}=5, s_{B}=3.5$, and $\frac{\mu}{r}=10$, we get $4 s_{A} \lambda<\left(3-8 \underline{\alpha}^{2}\right) s_{B}<4 s_{A} \lambda+\frac{s_{A}}{2\left(\frac{\mu}{r}\right)}$ and from the Lemma, the simple standard decreases initial expected welfare, increases expected welfare at the first discovery date if $B$ is discovered first, and then increases flow welfare after $\mathrm{A}$ is also discovered.

We shall now show that the contingent standard, in contrast, improves welfare at all dates. Consider the $\mathrm{c}$ game with licensing. If firm 1 discovers product $\mathrm{A}$ first and licenses it to firm 2 then both compete in the same product, yielding equilibrium profits and consumer surplus

$$
\begin{aligned}
& \Pi_{i}(A ; A)=\left(h_{1}+h_{2}\right) \bar{\theta}^{2} s_{A} / 9 \\
& C_{m}(A, A)=\left(2 h_{m} \bar{\theta}^{2} s_{A}\right) / 9
\end{aligned}
$$

Comparing (2.13) with (2.4), it is clear that $C_{m}(A, A)>C_{m}(A)$. Hence, from Theorem 6, the contingent standard is welfare enhancing if assumptions (A6) and (A7) are satisfied (ensuring licensing if $A$ is discovered first) for the chosen parameter values. We can show that (A6) and (A7) are equivalent to the following conditions, respectively.

$$
1-\left[9 h_{1} /\left(h_{1}+h_{2}\right)\right] \bar{\alpha}^{2}>5 /\left[4\left(\frac{\mu}{r}\right)\right]
$$




$$
4 s_{A}\left(h_{1}+h_{2}\right)>9 s_{B}\left(4 h_{1} \underline{\alpha}^{2}+h_{2}\right)
$$

These conditions are indeed satisfied for the parameters $s_{A}=5, s_{B}=3.5$, and $\frac{\mu}{r}=10$, when, say, $h_{1}=5, h_{2}=3, \underline{\theta}=.1$ and $k_{1 A}=k_{2 B}=1, k_{1 B}=6, k_{2 A}=45$. In sum, we have constructed an example where the contingent policy enhances welfare at all dates even though the simple standard policy is not time consistent. 


\section{Table 1}

\section{Payoffs to Firm 1}

Pavoffs to firm 1 if firm 2's strategy is to do nothing until after discovery of A or B by firm 1

$$
\begin{aligned}
& P_{1}(a, d)=\left(\mu F_{1 A}-k_{1 A}\right) /(r+\mu) \\
& P_{1}(b, d)=\left(\mu F_{1 B}-k_{1 B}\right) /(r+\mu) \\
& P_{1}(d, d)=0
\end{aligned}
$$

Payoffs to firm 1 if firm 2's strategy is to do R\&D on B

$$
\begin{aligned}
& P_{1}(a, b)=\left(\mu F_{1 A}+\mu S_{1 A}-k_{1 A}\right) /(r+2 \mu) \\
& P_{1}(b, b)=\left(\mu F_{1 B}+\mu S_{1 A}-k_{1 B}\right) /(r+2 \mu) \\
& P_{1}(d, b)=\mu S_{1 A} /(r+\mu)
\end{aligned}
$$

Payoffs to firm 1 if firm 2's strategy is to do R\&D on A

$$
\begin{aligned}
& P_{1}(a, a)=\left(\mu F_{1 A}+\mu S_{1 B}-k_{1 A}\right) /(r+2 \mu) \\
& P_{1}(b, a)=\left(\mu F_{1 B}+\mu S_{1 B}-k_{1 B}\right) /(r+2 \mu) \\
& P_{1}(d, a)=\mu S_{1 B} /(r+\mu)
\end{aligned}
$$

$P_{1}\left(s_{1}, s_{2}\right)$ is the expected payoff to firm 1 (discounted to $t=0$ ) if firm 1 uses $s_{1}$ and firm 2 uses $s_{2}$, $s_{i} \in\{a, b, d\}$. 


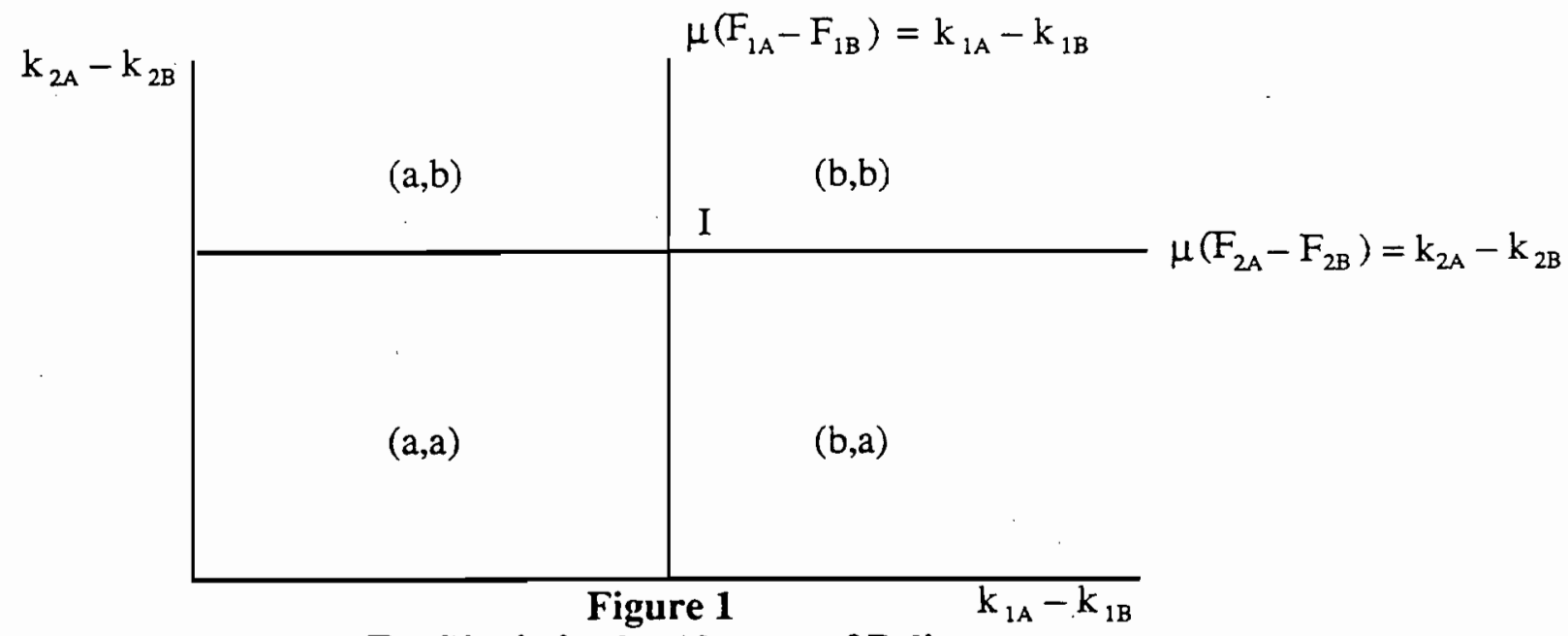

Equilibria in the Absence of Policy

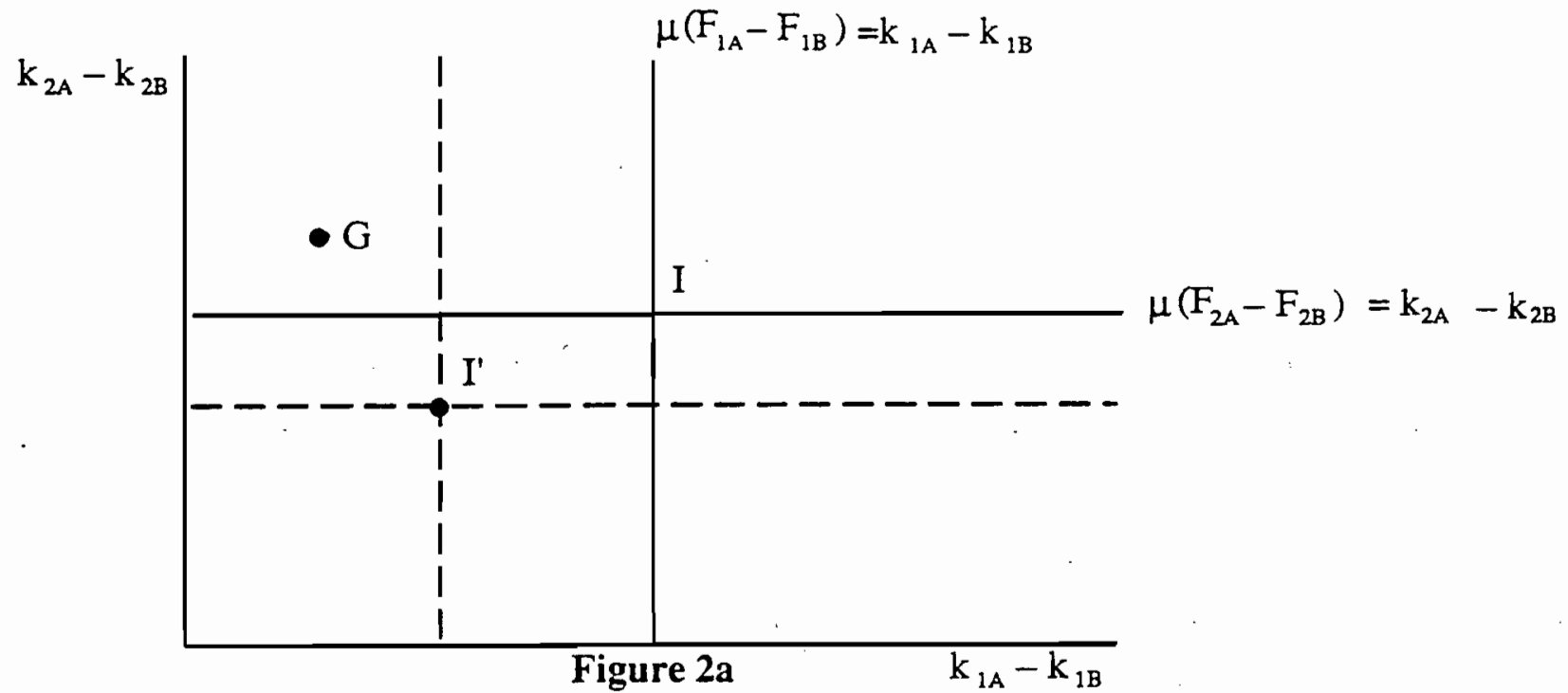

$\mathrm{B}$ as a Standard in Country 2

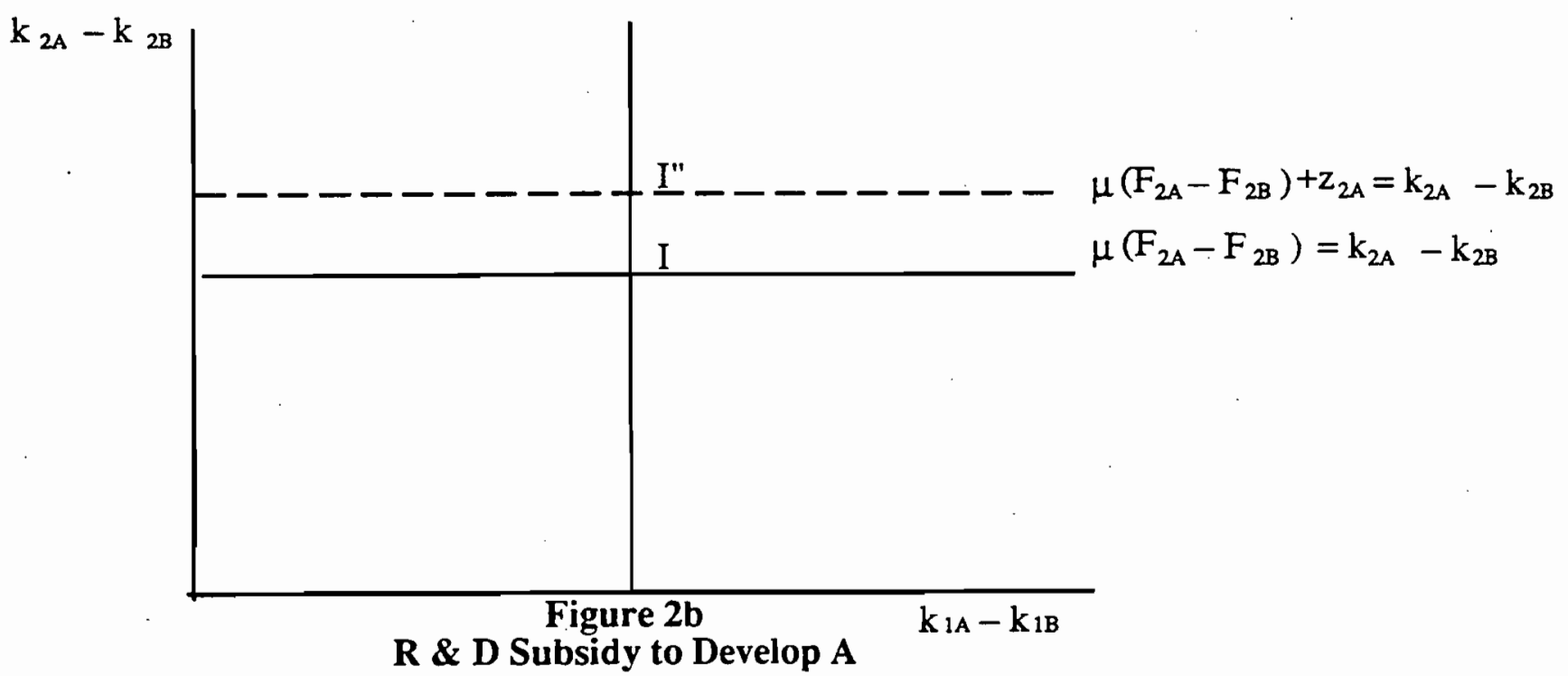


No. 93-101 Gordon M. Phillips, Robert J. Weiner

"Information and Normal Backwardation as Determinants of Trading Performance: Evidence from the North-Sea Oil Forward Market." 1994. The Economic Journal.

No. 93-102 Stephen R. Goldberg, Frank L. Heflin

"The Association Between the Level of International Diversification and Risk"

No. 93-103 John A. Carlson

"Risk Aversion, Foreign Exchange Speculation and Gambler's Ruin"

No. 93-104 John A. Carlson, Aasim M. Husain, Jeffrey A. Zimmerman

"Penalties and Exclusion in the Rescheduling and Forgiveness of International Loans"

No. 93-105 Kent D. Miller

"Industry and Country Effects on Manager's Perceptions of Environmental Uncertainties." 1993. Journal of International Business Studies, 24: 693-714.

No. 93-106 Stephen R. Goldberg and Joseph H. Godwin

"Foreign Currency Translation Under Two Cases-Integrated and Isolated Economies"

No. 93-107 Kent D. Miller

"A Comparison of Managers' Uncertainty Perceptions and Country Risk Indices"

No. 93-108 Jon D. Haveman

"The Effect of Trade Induced Displacement on Unemployment and Wages"

No. 93-109 Jon D. Haveman

"Some Welfare Effects of Dynamic Customs Union Formation"

No. 93-110 John A. Carlson, Insook Kim

"Central Banks' Expected Profits From Intervention

If you would like to request copies of specific papers, please contact the Center for International Business Education and Research, Purdue University, Krannert School of Management, West Lafayette, IN 47907.

(Phone: $317 / 494-4463$ or FAX: 317/494-9658) 
No. 94-001 Casper G. De Vries, Phillip A. Stork, Kees G. Koedijk

"Between Realignments and Intervention: The Belgian Franc in the European Monetary System"

No. 94-002 Casper G. de Vries, K. U. Leuven

"Stylized Facts of Nominal Exchange Rate Returns"

No. 94-003 Kent D. Miller

"Operational Flexibility Responses to Environmental Uncertainties"

No. 94-004 Kent D. Miller

"Economic Exposure and Integrated Risk Management"

No. 94-005 Kent D. Miller

"Diversification Responses to Environmental Uncertainties"

No. 94-006 John M. Hannon, Ing-Chung Huang, Bih-Shiaw Jaw

"International Human Resource Strategy and Its Determinants: The Case of Multinationals and Their Subsidiaries in Taiwan"

No. 94-007 John M. Hannon, Ing-Chung Huang, Bih-Shiaw Jaw

"International Human Resource Strategy andControl: The Case of Multinationals and Their

Subsidiaries"

No. 94-008 John M. Hannon, Yoko Sano

"Customer-Driven Human Resource Policies and Practices in Japan"

No. 94-009 John A. Carlson, Insook Kim

"Leaning Againsț the Wind: Do Central Banks Necessarily Lose?"

No. 94-010 John A. Carlson, David W. Schodt

"Beyond the Lecture: Case Teaching and the Learning of Economic Theory"

No. 94-011 Alok R. Chaturvedi, Hemant K. Jain, Derek L. Nazareth

"Key Information Systems Management Issues in Developing Countries: Differences in the Indian and US Contexts"

No. 94-012 Jon Haveman,

The Influence of Changing Trade Patterns on Displacements of Labor

No. 94-013 Stephen Goldberg

Financial Reporting for Foreign Exchange Derivatives

No. 94-014 Charles Noussair, Charles Plott, Raymond Riezman

Una investigacion experimental sobre la estructura del comercia interncional (Spanish Version)

Translated: An Experimental Investigation About the Structure of International Commerce

No. 94-015 - Marie Thursby, Richard Jensen

Patent Races, Product Standards, and International Competition

No. 94-016 Kent D. Miller, Jeffrey J. Reuer

Firm Strategy and Economic Exposure to Foreign Exchange Rate Movements

No.94-017 - John Hannon, Yoko Sano

The Determinants of Corporate Attractiveness in Japan 
No. 94-018 John Hannon, Ing-Chung Huang, Cheng-Chen Lin

The Mediating Effect of Pre/Post Assignment Acitivities on the Quality of Work Life of Expatriates:

Evidence for Managers in the P.R.C.

No. 94-019 John Hannon, Ing-Chung Huang, Cheng-Chen Lin

The Mediating Effects of Organization Commitment and Job Involvement on the Relationship Between Quality of Work Life and Customer Service Attitudes

No. 94-020 John A. Carlson, Marc Surchat

A Model for Filter-Rule Gains in Foreign Exchange Markets

No. 94-021 Ch.N. Noussair, Ch.R. Plott, R. Riezman

The Principles of Exchange Rate Determination in an International Finance Experiment

No. 94-022 Steven R. Goldberg, Joseph H. Godwin, Myung-Sun Kim, Charles A. Tritschler

On The Determinants of Corporate Hedging With Financial Derivatives

If you would like to request copies of specific papers, please contact the Center for International Business Education and Research, Purdue University, Krannert School of Management, West Lafayette, IN 47907.

(Phone: $317 / 494-4463$ or FAX: 317/494-9658) 